\title{
Potencial terapêutico e uso de plantas medicinais em uma área de Caatinga no estado do Ceará, nordeste do Brasil
}

\author{
RIBEIRO, D.A. ${ }^{\text {**; }}$ MACÊDO, D.G. ${ }^{1}$; OLIVEIRA, L.G.S. ${ }^{1}$; SARAIVA, M.E. ${ }^{1}$; OLIVEIRA, S.F. ${ }^{1}$; SOUZA, M.M.A. ${ }^{1}$; \\ MENEZES, I.R.A. ${ }^{2}$ \\ 1 Universidade Regional do Cariri (URCA), Programa de Pós-Graduação em Bioprospecção Molecular, \\ Departamento de Ciências Biológicas, Laboratório de Botânica, Rua Cel. Antônio Luiz Pimenta, 1161, Crato-CE, \\ CEP: 63105-000. ${ }^{2}$ Universidade Regional do Cariri (URCA), Departamento de Química Biológica, Laboratório \\ de Farmacologia e Químidca Molecular, Rua Cel. Antônio Luiz, 1161, Crato-CE, CEP: 63105-000. *daiany_ars@ \\ hotmail.com
}

\begin{abstract}
RESUMO: O presente trabalho visou o levantamento etnobotânico das plantas medicinais, verificando a versatilidade das espécies utilizadas e o consenso de uso e/ou conhecimento entre os informantes, do Distrito de Aratama, no Município de Assaré, Ceará. As informações etnobotânicas foram obtidas através de entrevistas estruturadas e semi-estruturadas com os moradores locais. Foram citadas 116 espécies com fins medicinais pertencentes a 103 gêneros e 58 famílias com destaque para Fabaceae (10ssp.), Asteraceae (7spp.) e Lamiaceae (6spp.). Entre as espécies levantadas, Mentha spicata L., Rosmarinus officinalis L., Allium sativum L., Bauhinia cheilantha (Bong.), Ximenea americana L., se destacaram como as mais versáteis dentro da comunidade. As indicações terapêuticas citadas foram agrupadas em 16 categorias de sistemas corporais, dos quais as Desordens mentais e comportamentais, as Afecções ou dores não definidas, os Transtornos do sistema respiratório, as Doenças de pele e do tecido celular subcutâneo, e os Transtornos do sistema sensorial (ouvidos), mostram maior concordância entre os informantes na utilização de espécies para tratar um sistema corporal especifico. Os resultados mostraram elevada riqueza da flora medicinal presente na caatinga. Neste sentido, torna-se necessária a intensificação de estudos que avaliem e consolidem as propriedades químicas e farmacológicas destas espécies.
\end{abstract}

Palavras-chave: Etnobotânica, semiárido, Importância Relativa, Fator Consenso de Informantes.

\begin{abstract}
Therapeutic potential and use of medicinal plants in an area of the Caatinga in the state of Ceará, northeastern Brazil. This study is about an ethnobotanical survey of medicinal plants, checking the versatility of the species used and the consensus of use and/or knowledge among informants from the Aratama District, in the municipality of Assaré, state of Ceará, Brazil. The ethnobotanical information was obtained through structured interviews and semi-structured interviews with local residents. Approximately, 116 species were mentioned for medicinal purposes, belonging to 103 genera and 58 families, especially Fabaceae (10ssp.), Asteraceae (7spp.) and Lamiaceae (6spp.). Among the surveyed species, Mentha spicata L., Rosmarinus officinalis L., Allium sativum L. and Bauhinia cheilantha (Bong.) Ximenea americana L. stood out as the most versatile in the community. The therapeutic indications mentioned were grouped into 16 categories of body systems; the mental and behavioral disorders, disorders or pain not defined, disorder of the respiratory system, skin diseases and subcutaneous tissue disorder, and disorder of the sensory system (ears) showed greater agreement among informants in the use of species to treat a specific body system. The results showed a high species richness of the medicinal flora present in the Brazilian Caatinga. Thus, it is necessary to intensify and consolidate studies assessing the chemical and pharmacological properties of these species.
\end{abstract}

Key words: Ethnobotany, Semiarid, Relative Importance, Informant Consensus Factor. 


\section{INTRODUÇÃO}

O Brasil é considerado um dos países de maior biodiversidade do planeta por possuir cerca de $20 \%$ do número total de espécies do mundo (Albuquerque et al., 2007a; Maciel et al., 2002). O número de espécies está estimado entre 350.000 e 550.000 , destas, apenas 55.000 catalogadas e distribuídas entre as diferentes regiões do país. Porém, parte desta diversidade de espécies ainda não foi investigada em relação as suas potencialidades terapêuticas, embora este seja um processo que vem evoluindo significativamente (Simões et al., 2003; Oliveira et al., 2009; Cartaxo et al., 2010).

A relação entre as pessoas e as plantas usadas na terapêutica local é um dos principais focos de interesse da etnobotânica. Esta ciência utiliza-se de diversas abordagens para ampliar o conhecimento sobre o uso da biodiversidade através dos saberes locais, aplicando diferentes estratégias, principalmente para a seleção de espécies propícias a bioprospecção (Shelley, 2009; Albuquerque, 2010).

As práticas médicas populares utilizam elementos naturais que, na maioria das vezes, são os únicos recursos disponíveis nos ambientes onde estão instaladas as comunidades (Leite et al., 2008; Albuquerque et al., 2010a; Roque et al., 2010) e, a constante busca por novos medicamentos com base nestas práticas tradicionais, tem-se mostrado eficaz (Albuquerque \& Hanazaki, 2006).

No nordeste as pesquisas etnobotânicas se encontram intensificadas principalmente em áreas de caatinga no estado de Pernambuco (Almeida \& Albuquerque, 2002; Almeida et al., 2005; Albuquerque, 2006; Albuquerque et al., 2007a), entretanto, ainda são poucos os estudos realizados em outros estados nordestinos. O Ceará apresenta cerca de $46 \%$ de plantas xerófilas da caatinga (IPECE, 2014), algumas delas endêmicas e ainda pouco exploradas pela farmacologia, mas que são conhecidas e utilizadas na medicina tradicional (Cartaxo et al., 2010).

A maioria das informações sobre as espécies medicinais da caatinga, hoje conhecidas e estudadas, foi obtida com ajuda de levantamentos etnobotânicos. A grande contribuição destes trabalhos é verificada nas diversas pesquisas que ressaltam as práticas de uso e sugestões de hipóteses que tentam explicar os sistemas médicos tradicionais das populações do semiárido nordestino (Almeida et al., 2005; Albuquerque et al., 2007a; Albuquerque, 2010; Roque et al., 2010; Alencar et al., 2010; Júnior et al., 2011). Neste caso, é interessante listar e explicar como são utilizadas as espécies medicinais que compõem áreas semiáridas ainda pouco exploradas, tornando-se necessário, principalmente, para subsidiar posteriores estudos químicos e farmacológicos.

Desta forma, considerando a importância de se conhecer a diversidade de plantas com finalidades terapêuticas e os poucos estudos para o estado do Ceará, o presente trabalho teve como objetivo levantar as espécies medicinais de acordo a utilização local, verificar a importância relativa, e analisar a concordância de conhecimento e uso destas espécies vegetais em uma área de caatinga no distrito de Aratama, município de Assaré - CE.

\section{MATERIAL E MÉTODOS}

\section{Área de Estudo}

O município de Assaré (6 $52^{\prime} 28^{\prime \prime} \mathrm{S} ; 39^{\circ}$ $52^{\prime} 30^{\prime \prime}$ W) está localizado no centro-sul do cariri, no estado do Ceará, Brasil, na mesorregião do sul cearense e microrregião da Chapada do Araripe; possui, além do distrito de Aratama, o distrito de Amaro. A sua superfície territorial é de $886 \mathrm{Km}^{2} \mathrm{e}$ apresenta altitude de $470 \mathrm{~m}$, clima quente semiárido, com temperatura média de $24^{\circ}$ a $26^{\circ} \mathrm{C}$ com período chuvoso de fevereiro a abril. Sua vegetação é constituída por Floresta Caducifólia Espinhosa, Floresta Subcaducifólia Tropical Pluvial e possui o Alto Jaguaribe como bacia hidrográfica (IPECE, 2010).

O presente trabalho foi desenvolvido com os moradores do distrito Aratama criado em 1913 (IPECE, 2010), localizado a $22 \mathrm{~km}$ de seu município sede, Assaré e a $358 \mathrm{~km}$ da capital. Aratama possui aproximadamente 180 famílias, com faixa etária que varia de zero a 102 anos, sendo de maioria católica. A população dispõe de uma escola de ensino fundamental e médio, uma creche, e um posto de saúde com visitas médicas semanais. $\mathrm{O}$ distrito está situado em ambiente de Caatinga e, como em outras comunidades rurais, apresenta histórico de uso de plantas medicinais. Neste distrito, dentre as principais atividades econômicas, está basicamente à agricultura de subsistência e atividades ligadas ao comércio informal.

\section{Coleta de Dados}

\section{Levantamento Etnobotânico}

Para a pesquisa utilizou-se entrevistas estruturadas e semiestruturadas com base em formulários padronizados (Martin, 1995; Albuquerque et al., 2010b; Cartaxo et al., 2010), e as informações sobre o conhecimento dos entrevistados foram concedidas após a leitura, permissão e assinatura do termo de consentimento livre e esclarecido pelos mesmos. Foram entrevistados 30 informantes, (homens e mulheres), com idades que variou 
de 18 a 91 anos. Aplicou-se a técnica "bola de neve", para selecionar os informantes principais, indicados a partir de um informante ou moradores, onde foram indicados outros informantes, assim sucessivamente, até que o conjunto de especialistas locais foi contemplado (Albuquerque et al., 2010b). O primeiro contato foi feito com a agente de saúde, onde a mesma indicou um informante e, a partir disso, se deu as decorrentes entrevistas.

As entrevistas se deram conforme observação direta (Albuquerque et al., 2008) e foram obtidas informações sobre as plantas usadas e/ou conhecidas para fins medicinais. A partir da técnica de lista livre, chegou-se as plantas usadas na terapêutica local, para quais foram obtidas informações acerca do uso, preparos, partes utilizadas, indicações e contraindicações, caso fossem de conhecimento dos mesmos. Para estimular os informantes a se recordarem de outras plantas foram utilizadas a indução não-específica, através de nova leitura e sugestão semântica (Albuquerque \& Lucena, 2004; Albuquerque et al. 2010a). Dados socioeconômicos sobre os informantes também foram registrados. As espécies citadas foram classificadas como nativas (espécies registradas em ambientes de caatinga) ou exóticas, que são as plantas de origem extracontinental naturalizadas, introduzidas intencionalmente ou não (Janni \& Bastien, 2004). As indicações terapêuticas das espécies estão agrupadas com base na classificação das doenças propostas pela Organização Mundial de Saúde (OMS, 2007).

\section{Levantamento Florístico}

As espécies medicinais citadas que se apresentavam em estágio reprodutivo e se encontravam disponíveis na comunidade, foram coletadas com a ajuda de informantes locais através de turnê guiada (Albuquerque et al. 2010b). O material vegetal coletado foi levado ao Laboratório de Botânica da Universidade Regional do Cariri, onde foi condicionado e tratado segundo as técnicas convencionais de herborização (Mori et al., 1989). A identificação se deu através de bibliografia especializada e por comparação com exsicatas de herbário, sendo posteriormente confirmada por especialistas. As espécies, depois de confirmada a identificação, foram incorporadas ao Herbário Caririense Dárdano de Andrade-Lima da Universidade Regional do Cariri (HCDAL-URCA).

\section{Análise de Dados} espécies

Versatilidade e concordância de uso das

A versatilidade das plantas medicinais identificadas foi calculada através do índice de importância relativa (IR) de acordo com a metodologia proposta por Bennett \& Prance (2000), sendo o "2" o valor máximo obtido por uma espécie. O cálculo da IR foi feito conforme a fórmula: IR= NSC+NP, onde IR corresponde a Importância Relativa, NSC é o Número de Sistemas Corporais determinado por uma certa espécie (NSCE), dividido pelo Número total de Sistemas Corporais tratados pela espécie mais Versátil (NSCEV); NP corresponde ao Número de Propriedades Atribuídas a uma determinada Espécie (NPE), dividido pelo Número total de Propriedades Atribuídas à Espécie mais Versátil (NPEV) (Silva et al., 2010; Almeida \& Albuquerque, 2002).

Para analisar a concordância de uso das espécies pelos citantes foi calculado o Fator Consenso de Informante ( $\mathrm{FCl}$ ) de acordo com a técnica de Totter \& Logan (1986). Para o cálculo do $\mathrm{FCl}$ foi utilizada a seguinte fórmula: $\mathrm{FCl}=$ nur - na/ nur -1 , Onde $\mathrm{FCl}$ refere-se ao Fator de Consenso dos Informantes, (nur) é o número de citações de usos em cada categoria e (na) corresponde ao número de espécies indicadas em cada categoria. Os valores de $\mathrm{FCl}$ variam de 0 a 1 .

As indicações terapêuticas de cada planta foram distribuídas dentro de 16 categorias de sistemas corporais descritas de acordo com Almeida e Albuquerque, (2002) e Cartaxo et al (2010): (ADND) Afecções Ou Dores Não Definidas; (DGEMN) Doença das Glândulas Endócrinas, da Nutrição e do Metabolismo; (DIP) Doenças Infecciosas e Parasitárias; (DMC) Desordens Mentais e Comportamentais; (DSOH) Doenças do Sangue e Órgão Hematopoiéticos; (DSOTC) Doença do Tecido Osteomuscular e Tecido Conjuntivo; (LEOCCE) Lesões, Envenenamentos e Outras Consequências de Causas Externas; (N) Neoplasias; (TSD) Transtorno do Sistema Digestório; (TSG) Transtorno do Sistema Geniturinário; (TSN) Transtorno do Sistema Nervoso; (TSR) Transtorno do Sistema Respiratório; (TSS(O)) Transtorno do Sistema Sensorial (ouvidos); (TSS(OLH)) Transtorno do Sistema Sensorial (olhos); (TSC): Transtorno do Sistema Circulatório; e (DPTCS): Doenças de Pele e Tecido Celular Subcutâneo.

\section{RESULTADOS E DISCUSSÃO}

\section{Levantamento Etnobotânico das Espécies Medicinais}

Foram levantadas 116 espécies com fins medicinais pertencentes a 103 gêneros e 58 famílias (Tabela 1). Trata-se de número de espécies expressivo quando comparado a outros levantamentos realizados em áreas de caatinga em que o número de espécies variou entre 57 a 119 
espécies (Morais et al., 2005; Almeida et al. 2005; Silva et al. 2006; Albuquerque \& Oliveira, 2007; Cartaxo et al., 2010; Roque et al., 2010; Oliveira et al., 2010a; Marinho et al., 2011).

A família Fabaceae apresentou o maior número de espécies (10spp.), seguida de Astercaceae (7spp.) e Lamiaceae (6spp.). As famílias mais representativas neste trabalho também foram referenciadas em outros estudos realizados em áreas de caatinga (Albuquerque et al., 2005; Almeida et al. 2006; Agra et al., 2007; Mosca \& Loiola, 2009; Roque et al., 2010). A predominância de espécies de uma mesma família em determinada região, mesmo as que possuem ampla distribuição, faz com que se tenha maior probabilidade de serem utilizadas, além disso, mostra o grande potencial medicinal destas espécies, já que possuem recorrência de uso. Dos 103 gêneros, Solanum (5spp.) foi o mais diversificado, seguido de Croton e Citrus (3spp. cada).

Dentre as espécies, 39 foram consideradas nativas e 77 exóticas. O grande número de espécies exóticas sobressaindo às nativas também é comum em outros levantamentos realizados em áreas de caatinga que, além de considerarem espécies exóticas, as classificam ainda como cultivada, adquiridas, ou espontâneas (Almeida \& Albuquerque, 2002; Albuquerque et al., 2007a; Cartaxo et al. 2010). Albuquerque (2006) argumenta que a prevalência do uso de espécies exóticas pode estar associada à necessidade de ampliação do estoque farmacêutico local. Para Alencar et al. (2010) a hipótese de diversificação é a que melhor explica a inclusão de plantas exóticas em farmacopéias tradicionais na caatinga, sugerindo que as comunidades tradicionais incorporem plantas exóticas para fins terapêuticos com o intuito de ampliar as possibilidades de cura para as suas afecções. Outra justificativa é condicionada ao fato de que as espécies exóticas se apresentam disponíveis e de serem facilmente cultivadas, sendo possível muitas vezes sanar problemas que não seriam resolvidos pelo uso de espécies locais (Cartaxo et al, 2010), sendo esta justificativa a que mais se aplica a este estudo. Na comunidade estudada o baixo número de espécies nativas utilizadas está relacionada a pouca ocorrência das mesmas na localidade. Desta forma, o uso de espécies exóticas pela população se torna mais viável e comum, principalmente pela disponibilidade e fácil cultivo, e também pela transmissão de informações.

Em relação às partes das plantas utilizadas, a folha recebeu maior número de citações de uso (62), seguida da casca (24), semente (19), raiz (17), fruto (13) e entrecasca (12). O uso preponderante das folhas pode estar relacionado com o fato da maior parte das espécies utilizadas na comunidade serem exóticas e cultivadas de hábito herbáceo e apresentar folhas durante o ano todo, independente do clima (Roque et al., 2010). O uso de casca é frequentemente citado em outros estudos etnobotânicos do semiárido nordestino, como sendo a segunda parte vegetal mais utilizada. Esta situação pode ser justificada por vários aspectos, tais como: a interferência de fatores ambientais, a sazonalidade climática, e os fatores culturais de uma região, que, atrelada a impossibilidade de se ter folhas durante todo o ano, influencia na escolha de uma espécie ou parte vegetal para um determinado tratamento terapêutico (Silva \& Albuquerque, 2005; Albuquerque et al., 2008; Lucena et al, 2008; Cartaxo et al. 2010).

Os informantes citaram diferentes formas de preparo na utilização das plantas medicinais (11). O preparo de chás correspondeu a mais de $50 \%$ dos onze modos de preparo; decocção apresentou $46,11 \%$, e infusão $9,84 \%$, principalmente das folhas. Casca, entrecasca do caule ou do fruto, raízes e sementes, que geralmente são utilizadas de molho $(13,47 \%)$, foram o segundo modo de preparo mais citado. O restante dos modos de preparo (lambedor, sumo, raspas ou pó, cataplasma, óleo, tinturas, suco e látex com água), juntos, correspondeu a $30,03 \%$. Em outros levantamentos etnobotânicos, os chás representam o modo de preparo mais citados entre os informantes (Cartaxo et al., 2010; Oliveira et al., 2010b; Marinho et al., 2011). A escolha do preparo provavelmente está relacionada com a disponibilidade da parte utilizada, no caso, das espécies exóticas que apresentam folhas durante todo o ano e as nativas da caatinga que disponibilizam suas cascas (Cartaxo et al., 2010). O preparo também pode estar relacionado com as características da planta, e, de acordo com Alencar et al. (2010), as árvores tem tendência a possuir maior quantidade de compostos químicos que as herbáceas. Com frequência a preparação simples é vista como modo eficaz.

\section{Versatilidade das Espécies Medicinais}

Entre todas as espécies indicadas, 66 $(56,89 \%)$ são empregadas para mais de um problema de saúde, se mostrando versáteis dentro da comunidade, enquanto que $50(43,10 \%)$ apresentaram uma única utilidade cada (Tabela 1). Quatorze espécies obtiveram grande importância relativa em relação a sua utilização medicinal com IR $>1$, sendo indicadas para tratamento de até oito sistemas corporais. Estas espécies são consideradas muito importantes para a comunidade devido ao grande numero de indicações terapêuticas. O restante, 102 espécies, apresentaram IR variando de 0,19 a 1. 
TABELA 1. Lista de espécies medicinais indicadas pelos entrevistados do Distrito de Aratama no município de Assaré, Ceará, Brasil.

\begin{tabular}{|c|c|c|c|c|c|c|c|c|}
\hline $\begin{array}{l}\text { Família e Nome } \\
\text { Científico }\end{array}$ & Nome Popular & ES & HB & $\begin{array}{c}\text { Parte } \\
\text { utilizada }\end{array}$ & Preparo & $\begin{array}{l}\text { Utilização/ } \\
\text { Indicação popular }\end{array}$ & IR & NH \\
\hline \multicolumn{9}{|l|}{ Acanthaceae } \\
\hline Justicia sp. & Anador & Ex & $\mathrm{He}$ & Fo & Decocção & $\begin{array}{l}\text { Dores em geral, dor de } \\
\text { cabeça }\end{array}$ & 0,39 & $\mathrm{nc}$ \\
\hline \multicolumn{9}{|l|}{ Alismataceae } \\
\hline $\begin{array}{l}\text { Echinodorus grandiflorus } \\
\text { Mitch }\end{array}$ & Chapéu-de-couro & Ex & $\mathrm{He}$ & Fo & Decocção & Dor nos rins & 0,19 & ncp \\
\hline \multicolumn{9}{|l|}{ Anacardiaceae } \\
\hline $\begin{array}{l}\text { Anacardium ooccidentale } \\
\text { L. }\end{array}$ & Caju & $\mathrm{Na}$ & $\operatorname{Ar}$ & $\mathrm{Cc}, \mathrm{Ec}$ & $\begin{array}{l}\text { Decocção ou } \\
\text { infusão }\end{array}$ & $\begin{array}{l}\text { Inflamação do ovário, } \\
\text { inflamação em geral, } \\
\text { ferimentos }\end{array}$ & 0,58 & 8367 \\
\hline $\begin{array}{l}\text { Myracrodruon urundeuva } \\
\text { Allemão }\end{array}$ & Aroeira & $\mathrm{Na}$ & $\mathrm{Ar}$ & $\begin{array}{l}\text { Fo, Cc } \\
\text { e Ec }\end{array}$ & $\begin{array}{l}\text { Decocção, } \\
\text { infusão, } \\
\text { de molho, } \\
\text { tintura }\end{array}$ & $\begin{array}{l}\text { Inflamação uterina, } \\
\text { inflamação, tosse, inflamação } \\
\text { do ovário, inflamação } \\
\text { ginecológica, cicatrizante, } \\
\text { queimadura }\end{array}$ & 1,00 & 8338 \\
\hline $\begin{array}{l}\text { Schinopsis brasiliensis } \\
\text { Engl. Var. }\end{array}$ & Braúna & $\mathrm{Na}$ & $\mathrm{Ar}$ & Fo & Decocção & $\begin{array}{l}\text { Dores no estômago, dores no } \\
\text { fígado }\end{array}$ & 0,39 & 8361 \\
\hline Spondias purpurea L. & Siriguela & Ex & $\mathrm{Ar}$ & Fo & Decocção & $\begin{array}{l}\text { Diarreia, dor de barriga, } \\
\text { gastrite }\end{array}$ & 0,26 & 8915 \\
\hline $\begin{array}{l}\text { Spondias tuberosa Arr. } \\
\text { Can }\end{array}$ & Imbu & $\mathrm{Na}$ & $\mathrm{Ar}$ & Rat & Infusão & Corrimento de mulher & 0,19 & ncp \\
\hline \multicolumn{9}{|l|}{ Annonaceae } \\
\hline Annona muricata L. & Graviola & Ex & $\mathrm{Ar}$ & Fo & Decocção & $\begin{array}{l}\text { Pressão alta, emagrecimento, } \\
\text { febre }\end{array}$ & 0,59 & nc \\
\hline Annona squamosa L. & Pinha & Ex & $\operatorname{Ar}$ & Fo & Decocção & Diarreia & 0,19 & 8341 \\
\hline $\begin{array}{l}\text { Guatteria australis A. } \\
\text { St.Hil. }\end{array}$ & Imbiriba & Ex & $\mathrm{He}$ & Fo & Decocção & $\begin{array}{l}\text { Dor no estômago, cólica geral, } \\
\text { dor em geral }\end{array}$ & 0,46 & $\mathrm{nc}$ \\
\hline \multicolumn{9}{|l|}{ Apiaceae } \\
\hline Anethum graveolens L. & Endro & Ex & $\mathrm{He}$ & $\mathrm{Se}$ & Decocção & $\begin{array}{l}\text { Gastura, pressão alta, } \\
\text { calmante }\end{array}$ & 0,58 & 8363 \\
\hline Coriandrum sativum L. & Coentro & Ex & $\mathrm{He}$ & $\mathrm{Se}$ & Decocção & Diarreia & 0,19 & $\mathrm{nc}$ \\
\hline Pimpinella anisum $\mathrm{L}$. & Erva-doce & Ex & $\mathrm{He}$ & Fo e Se & $\begin{array}{l}\text { Decocção, } \\
\text { torrado (em pó) } \\
\text { com água }\end{array}$ & $\begin{array}{l}\text { Vômito, dor no estômago, } \\
\text { gastura }\end{array}$ & 0,34 & 8366 \\
\hline \multicolumn{9}{|l|}{ Apocynaceae } \\
\hline $\begin{array}{l}\text { Catharanthus roseus (L.) } \\
\text { Don. }\end{array}$ & Boa-noite & Ex & $\mathrm{Sb}$ & Fo & Sumo & Dor de ouvido & 0,19 & $\mathrm{nc}$ \\
\hline $\begin{array}{l}\text { Himatanthus drasticus } \\
\text { (Mart.) Plumel }\end{array}$ & Janaguba & $\mathrm{Na}$ & $\mathrm{Ar}$ & La & $\begin{array}{l}\text { Látex com } \\
\text { água }\end{array}$ & Inflamação & 0,19 & ncp \\
\hline \multicolumn{9}{|l|}{ Arecaceae } \\
\hline $\begin{array}{l}\text { Acrocomia aculeata } \\
\text { (Jacq.) Lodd. ex Mart. }\end{array}$ & Macaúba & $\mathrm{Na}$ & $\mathrm{Ar}$ & $\mathrm{FI}$ & Decocção & Dor em geral, tosse & 0,39 & nc \\
\hline Cocos nucifera L. & Coco & Ex & $\mathrm{Ar}$ & $\mathrm{Ec}, \mathrm{Fr}, \mathrm{FI}$ & Decocção & Infecção urinária, dor nos rins & 0,19 & $\mathrm{nc}$ \\
\hline Asteraceae & & & & & & & & \\
\hline
\end{tabular}


TABELA 1. Lista de espécies medicinais indicadas pelos entrevistados do Distrito de Aratama no município de Assaré, Ceará, Brasil.

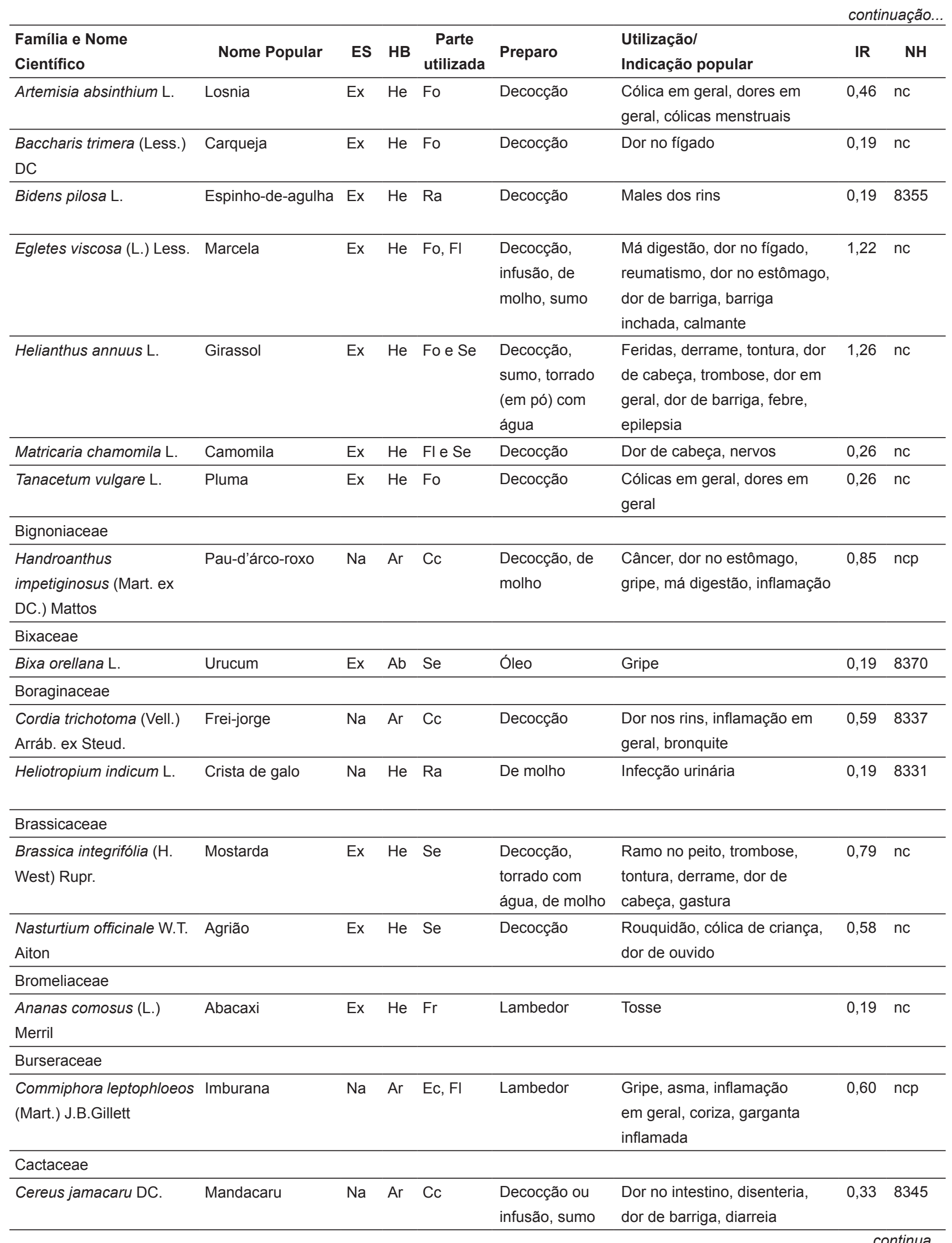


TABELA 1. Lista de espécies medicinais indicadas pelos entrevistados do Distrito de Aratama no município de Assaré, Ceará, Brasil.

continuação...

\begin{tabular}{|c|c|c|c|c|c|c|c|c|}
\hline $\begin{array}{l}\text { Família e Nome } \\
\text { Científico }\end{array}$ & Nome Popular & ES & HB & $\begin{array}{c}\text { Parte } \\
\text { utilizada }\end{array}$ & Preparo & $\begin{array}{l}\text { Utilização/ } \\
\text { Indicação popular }\end{array}$ & IR & NH \\
\hline $\begin{array}{l}\text { Opuntia cochenillifera } \\
\text { (L.) Mill }\end{array}$ & Palma & Ex & $\mathrm{He}$ & $\mathrm{Cc}$ & De molho & Disenteria, dor de barriga & 0,19 & $\mathrm{nc}$ \\
\hline \multicolumn{9}{|l|}{ Cleomaceae } \\
\hline $\begin{array}{l}\text { Tarenaya spinosa (Jacq.) } \\
\text { Raf. }\end{array}$ & Mussambê & $\mathrm{Na}$ & $\mathrm{Sb}$ & $\begin{array}{l}\text { Fo, FI } \\
\text { e Ra }\end{array}$ & $\begin{array}{l}\text { Decocção, } \\
\text { infusão, de } \\
\text { molho }\end{array}$ & $\begin{array}{l}\text { Bronquite, inflamação, gripe, } \\
\text { umbigo inflamado }\end{array}$ & 0,53 & 8328 \\
\hline \multicolumn{9}{|l|}{ Caprifoliaceae } \\
\hline $\begin{array}{l}\text { Sambucus australis } \\
\text { Cham. \& Schlecht }\end{array}$ & Sabugueiro & Ex & $\mathrm{Ab}$ & $\mathrm{FI}$ & Decocção & Cólicas em geral & 0,19 & nc \\
\hline \multicolumn{9}{|l|}{ Caricaceae } \\
\hline Carica papaya L. & Mamão & Ex & $\mathrm{Ab}$ & $\begin{array}{l}\mathrm{FI}, \mathrm{Se}, \mathrm{Fo} \\
\text { (broto), } \\
\mathrm{Fr}\end{array}$ & $\begin{array}{l}\text { Decocção e } \\
\text { lambedor }\end{array}$ & $\begin{array}{l}\text { Gripe, má digestão, cólicas de } \\
\text { criança, intestino preso }\end{array}$ & 0,60 & nc \\
\hline \multicolumn{9}{|l|}{ Caryocaraceae } \\
\hline $\begin{array}{l}\text { Caryocar coriaceum } \\
\text { Wittm. }\end{array}$ & Pequi & $\mathrm{Na}$ & $\mathrm{Ar}$ & $\mathrm{Fr}$ & Óleo, lambedor & Gripe, pancadas & 0,39 & ncp \\
\hline \multicolumn{9}{|l|}{ Capparaceae } \\
\hline Capparis flexuosa (L.) L. & Feijão-bravo & $\mathrm{Na}$ & $\mathrm{Sb}$ & Fo & Decocção & Febre, depurativo & 0,39 & 8334 \\
\hline \multicolumn{9}{|l|}{ Chenopodiaceae } \\
\hline $\begin{array}{l}\text { Chenopodium } \\
\text { ambrosioides L. }\end{array}$ & Mastruz & Ex & $\mathrm{He}$ & Fo & $\begin{array}{l}\text { Decocção, } \\
\text { sumo, suco } \\
\text { com água ou } \\
\text { leite }\end{array}$ & $\begin{array}{l}\text { Reumatismo, úlcera, } \\
\text { pancadas, cicatrizante, } \\
\text { inflamação, dor no estômago, } \\
\text { fraturas }\end{array}$ & 1,12 & 8347 \\
\hline \multicolumn{9}{|l|}{ Combretaceae } \\
\hline Terminalia catappa L. & Castanhola & Ex & $\mathrm{Ar}$ & Fo & Decocção & Problema nos rins & 0,19 & ncp \\
\hline \multicolumn{9}{|l|}{ Convolvulaceae } \\
\hline $\begin{array}{l}\text { Ipomoea batatas (L.) } \\
\text { Lam. }\end{array}$ & Batata-doce & Ex & $\mathrm{He}$ & Fo & Decocção & Dente inflamado & 0,19 & nc \\
\hline \multicolumn{9}{|l|}{ Crassulaceae } \\
\hline $\begin{array}{l}\text { Kalanchoe brasiliensis } \\
\text { Cambess. }\end{array}$ & Malva-corona & Ex & $\mathrm{He}$ & Fo e Ra & $\begin{array}{l}\text { Decocção, } \\
\text { suco, } \\
\text { lambedor, } \\
\text { cataplasma }\end{array}$ & $\begin{array}{l}\text { Ferimentos na pele, } \\
\text { inflamação, gripe, úlcera, } \\
\text { dores em geral, dor na barriga }\end{array}$ & 1,04 & nc \\
\hline Sedum praealtum A. DC. & Bálsamo & Ex & $\mathrm{He}$ & Fo & Decocção & Gripe, gastrite & 0,39 & nc \\
\hline \multicolumn{9}{|l|}{ Cucurbitaceae } \\
\hline Cucurbita pepo L & Jerimum & Ex & $\mathrm{He}$ & $\mathrm{Se}$ & $\begin{array}{l}\text { Pilada para } \\
\text { decocção }\end{array}$ & Dor de barriga, gastura & 0,26 & ncp \\
\hline Citrullus vulgaris Schrad. & Melancia & Ex & $\mathrm{He}$ & $\mathrm{Se}$ & Decocção & Dor no estômago & 0,19 & nc \\
\hline \multicolumn{9}{|l|}{ Euphorbiaceae } \\
\hline Croton sp. & Velame & $\mathrm{Na}$ & $\mathrm{Ab}$ & Fo & Decocção & $\begin{array}{l}\text { Dores em geral, inflamação } \\
\text { em geral }\end{array}$ & 0,26 & 8340 \\
\hline
\end{tabular}


TABELA 1. Lista de espécies medicinais indicadas pelos entrevistados do Distrito de Aratama no município de Assaré, Ceará, Brasil.

continuação...

\begin{tabular}{|c|c|c|c|c|c|c|c|c|}
\hline \multirow[b]{2}{*}{$\begin{array}{l}\text { Família e Nome } \\
\text { Científico }\end{array}$} & \multirow[b]{2}{*}{ Nome Popular } & \multirow[b]{2}{*}{ ES } & \multirow[b]{2}{*}{ HB } & \multirow[b]{2}{*}{$\begin{array}{c}\text { Parte } \\
\text { utilizada }\end{array}$} & \multirow[b]{2}{*}{ Preparo } & \multirow[b]{2}{*}{$\begin{array}{l}\text { Utilização/ } \\
\text { Indicação popular }\end{array}$} & \\
\hline & & & & & & & IR & NH \\
\hline $\begin{array}{l}\text { Croton conduplicatus } \\
\text { Kunth }\end{array}$ & Quebra-faca & $\mathrm{Na}$ & $\mathrm{Ab}$ & Fo e Cc & $\begin{array}{l}\text { Decocção, } \\
\text { cataplasma }\end{array}$ & $\begin{array}{l}\text { Inflamação no nariz, dor de } \\
\text { cabeça }\end{array}$ & 0,39 & 8330 \\
\hline $\begin{array}{l}\text { Croton blanchetianus } \\
\text { Baill. }\end{array}$ & Marmeleiro & $\mathrm{Na}$ & $\mathrm{Ar}$ & $\begin{array}{l}\text { Fo, Cc } \\
\text { e Ec }\end{array}$ & $\begin{array}{l}\text { Decocção, de } \\
\text { molho, sumo }\end{array}$ & $\begin{array}{l}\text { Hemorragia em geral, } \\
\text { fígado, dor na barriga, dor de } \\
\text { estômago }\end{array}$ & 0,65 & 8333 \\
\hline Manihot esculenta Crantz. & Mandioca & Ex & $\mathrm{Ar}$ & Fo e Ra & Decocção & Diarréia, gastrite & 0,26 & $\mathrm{nc}$ \\
\hline Ricinus communis $\mathrm{L}$. & Mamona & $\mathrm{Na}$ & $\mathrm{He}$ & Fo & $\begin{array}{l}\text { De molho, } \\
\text { sumo }\end{array}$ & $\begin{array}{l}\text { Garganta inflamada, tônico } \\
\text { capilar }\end{array}$ & 0,39 & $\mathrm{nc}$ \\
\hline \multicolumn{9}{|l|}{ Fabaceae } \\
\hline $\begin{array}{l}\text { Amburana cearensis } \\
\text { (Allemão) A. C. }\end{array}$ & Imburana-de-cheiro & $\mathrm{Na}$ & $\mathrm{Ar}$ & $\begin{array}{l}\mathrm{Fr}, \mathrm{Se} \\
\mathrm{Cc} \text { e Ec }\end{array}$ & $\begin{array}{l}\text { Decocção, } \\
\text { infusão, } \\
\text { de molho, } \\
\text { lambedor, } \\
\text { cataplasma }\end{array}$ & $\begin{array}{l}\text { Gripe, inflamação, dor de } \\
\text { cabeça, coriza }\end{array}$ & 0,65 & $\mathrm{ncp}$ \\
\hline $\begin{array}{l}\text { Anadenanthera colubrina } \\
\text { (Vell.) Brenan }\end{array}$ & Angico & $\mathrm{Na}$ & $\mathrm{Ar}$ & $\begin{array}{l}\mathrm{Re}, \mathrm{Cc} \\
\mathrm{e} \mathrm{Ec}\end{array}$ & $\begin{array}{l}\text { Decocção, } \\
\text { casca torrada } \\
\text { (em pó), } \\
\text { de molho e } \\
\text { lambedor }\end{array}$ & $\begin{array}{l}\text { Garganta inflamada, gripe, } \\
\text { tosse, febre, inflamação }\end{array}$ & 0,67 & 8329 \\
\hline $\begin{array}{l}\text { Bauhinia cheilantha } \\
\text { (Bong.) Steud. }\end{array}$ & Mororó & $\mathrm{Na}$ & $\mathrm{Ar}$ & $\begin{array}{l}\text { Fo, Cc e } \\
\text { Ec, FI }\end{array}$ & $\begin{array}{l}\text { Decocção, } \\
\text { infusão, de } \\
\text { molho, raspa } \\
\text { com água, } \\
\text { lambedor }\end{array}$ & $\begin{array}{l}\text { Diabetes, gripe, nervos, } \\
\text { pressão alta, dor nos rins, } \\
\text { infecção urinária, inflamação }\end{array}$ & 1,29 & 8373 \\
\hline Erythina velutina willd & Mulungu & $\mathrm{Na}$ & $\mathrm{Ar}$ & Cc & $\begin{array}{l}\text { Raspas de } \\
\text { molho }\end{array}$ & Dor de dente & 0,19 & ncp \\
\hline Hymenaea courbaril L. & Jatobá & $\mathrm{Na}$ & $\mathrm{Ar}$ & $\begin{array}{l}\mathrm{Fr}, \mathrm{Cc} \\
\mathrm{e} \mathrm{Ec}\end{array}$ & $\begin{array}{l}\text { Tintura, de } \\
\text { molho }\end{array}$ & $\begin{array}{l}\text { Tosse, aumenta o sangue, } \\
\text { gripe, anemia }\end{array}$ & 0,65 & ncp \\
\hline $\begin{array}{l}\text { Libidibia ferrea (Mart. ex } \\
\text { Tul.) L.P. Queiroz }\end{array}$ & Pau-ferro & $\mathrm{Na}$ & $\mathrm{Ar}$ & $\mathrm{Cc}$ & De molho & Dor nas pernas & 0,19 & 8344 \\
\hline $\begin{array}{l}\text { Mimosa tenuiflora (Mart.) } \\
\text { Benth. }\end{array}$ & Jurema-preta & $\mathrm{Na}$ & $\mathrm{Ab}$ & Cc e Ec & $\begin{array}{l}\text { Decocção, de } \\
\text { molho }\end{array}$ & $\begin{array}{l}\text { Inflamação ginecológica, } \\
\text { ferimentos, dor de dente }\end{array}$ & 0,83 & 8352 \\
\hline $\begin{array}{l}\text { Prosopis juliflora (Sw) } \\
\text { D.C. }\end{array}$ & Algaroba & Ex & $\mathrm{Ar}$ & Fo e FI & Decocção & Dor de barriga & 0,19 & $\mathrm{ncp}$ \\
\hline $\begin{array}{l}\text { Senegalia tenuifolia (L.) } \\
\text { Britton \& Rose }\end{array}$ & Unha-de-gato & $\mathrm{Na}$ & $\mathrm{Ar}$ & $\begin{array}{l}\mathrm{F} \quad \mathrm{O} \\
\text { (broto) }\end{array}$ & Decocção & $\begin{array}{l}\text { Dores reumáticas, dor na } \\
\text { coluna }\end{array}$ & 0,26 & 8371 \\
\hline $\begin{array}{l}\text { Stryphnodendron } \\
\text { coriaceum Benth. }\end{array}$ & Barbatimão & $\mathrm{Na}$ & $\mathrm{Ar}$ & Cc & De molho & Inflamação & 0,19 & $\mathrm{ncp}$ \\
\hline Lamiaceae & & & & & & & & \\
\hline
\end{tabular}


TABELA 1. Lista de espécies medicinais indicadas pelos entrevistados do Distrito de Aratama no município de Assaré, Ceará, Brasil.

continuação...

\begin{tabular}{|c|c|c|c|c|c|c|c|c|}
\hline \multirow[b]{2}{*}{$\begin{array}{l}\text { Família e Nome } \\
\text { Científico }\end{array}$} & \multirow[b]{2}{*}{ Nome Popular } & \multirow[b]{2}{*}{ ES } & \multirow[b]{2}{*}{ HB } & \multirow[b]{2}{*}{$\begin{array}{c}\text { Parte } \\
\text { utilizada }\end{array}$} & \multirow[b]{2}{*}{ Preparo } & \multirow[b]{2}{*}{$\begin{array}{l}\text { Utilização/ } \\
\text { Indicação popular }\end{array}$} & \\
\hline & & & & & & & IR & $\mathrm{NH}$ \\
\hline Mentha spicata L. & Hortelã & Ex & $\mathrm{He}$ & Fo & $\begin{array}{l}\text { Lambedor e } \\
\text { decocção }\end{array}$ & $\begin{array}{l}\text { Ramo do peito, febre, } \\
\text { colesterol alto, fraqueza, } \\
\text { gripe, dor de cabeça, garganta } \\
\text { inflamada, acidente vascular } \\
\text { cerebral, trombose, derrame, } \\
\text { problemas de coração, } \\
\text { ramo no olho, calmante, má } \\
\text { digestão, cólica menstrual }\end{array}$ & 2,00 & ncp \\
\hline Ocimum basilicum L. & Manjericão & Ex & $\mathrm{Sb}$ & Fo & Sumo & $\begin{array}{l}\text { Dor de ouvido, gripe, } \\
\text { conjuntivite }\end{array}$ & 0,58 & $\mathrm{nc}$ \\
\hline Ocimum gratissimum L. & Alfavaca & Ex & $\mathrm{He}$ & Fo & $\begin{array}{l}\text { De molho e } \\
\text { decocção }\end{array}$ & Inflamação, coriza & 0,39 & 8362 \\
\hline $\begin{array}{l}\text { Plectranthus barbatus } \\
\text { Andrews. }\end{array}$ & Malva sete dores & Ex & $\mathrm{He}$ & Fo & $\begin{array}{l}\text { Decocção, } \\
\text { infusão }\end{array}$ & $\begin{array}{l}\text { Dor no estômago, má } \\
\text { digestão, dores em geral, } \\
\text { cólica menstrual }\end{array}$ & 0,60 & 8374 \\
\hline $\begin{array}{l}\text { Pogostemon cablin } \\
\text { (Blanco) Benth. }\end{array}$ & Patchuli & Ex & $\mathrm{He}$ & $\mathrm{Se}$ & Decocção & Doenças do coração & 0,19 & $\mathrm{nc}$ \\
\hline Rosmarinus officinalis $\mathrm{L}$. & Alecrim & Ex & $\mathrm{Sb}$ & Fo e Ec & Decocção & $\begin{array}{l}\text { Dor de cabeça, gripe, } \\
\text { nervosismo, problemas no } \\
\text { coração, dores em geral, } \\
\text { trombose, cólica de criança, } \\
\text { febre, dores reumática }\end{array}$ & 1,51 & 8358 \\
\hline \multicolumn{9}{|l|}{ Lauraceae } \\
\hline $\begin{array}{l}\text { Cinnamomum zeylanicum } \\
\text { Blume }\end{array}$ & Canela & Ex & $\mathrm{Ar}$ & $\mathrm{Cc}$ & Decocção & Calmante, pressão alta & 0,39 & $\mathrm{nc}$ \\
\hline Laurus nobilis $\mathrm{L}$. & Louro & Ex & $A b$ & Fo & Decocção & Cólica menstrual & 0,19 & 8372 \\
\hline Persea americana Mill. & Abacate & Ex & $\mathrm{Ar}$ & Fo & $\begin{array}{l}\text { Decocção e } \\
\text { sumo }\end{array}$ & $\begin{array}{l}\text { Inflamações na boca, pedras } \\
\text { nos rins, infecção urinária, dor } \\
\text { nos rins }\end{array}$ & 0,53 & $\mathrm{ncp}$ \\
\hline \multicolumn{9}{|l|}{ Leguminosae } \\
\hline Poecilanthe sp. & Ingazeira & Ex & $\mathrm{Ar}$ & $\mathrm{Cc}$ & De molho & Inchaço nas pernas & 0,19 & ncp \\
\hline \multicolumn{9}{|l|}{ Liliaceae } \\
\hline Allium cepa L. & Cebola-branca & Ex & $\mathrm{He}$ & Fo e FI & $\begin{array}{l}\text { Decocção ou } \\
\text { lambedor }\end{array}$ & Gripe, bronquite, sinusite & 0,33 & $\mathrm{nc}$ \\
\hline Allium sativum $\mathrm{L}$. & Alho & Ex & $\mathrm{He}$ & $\mathrm{Fr}$ & $\begin{array}{l}\text { Decocção, } \\
\text { lambedor e } \\
\text { infusão }\end{array}$ & $\begin{array}{l}\text { Gripe e garganta inflamada, } \\
\text { pressão alta, cólicas, } \\
\text { emagrecer, dor de cabeça, } \\
\text { febre, câncer }\end{array}$ & 1,32 & $\mathrm{nc}$ \\
\hline Aloe vera (L.) Burm. f. & Babosa & Ex & $\mathrm{He}$ & Fo & $\begin{array}{l}\text { Sumo, } \\
\text { lambedor }\end{array}$ & $\begin{array}{l}\text { Inflamação, gripe, afina o } \\
\text { sangue, tônico capilar, câncer, } \\
\text { hemorroidas, dores em geral }\end{array}$ & 1,25 & $\mathrm{nc}$ \\
\hline \multicolumn{9}{|l|}{ Malvaceae } \\
\hline Gossypium hirsutum L. & Algodão-brabo & Ex & $\mathrm{Ar}$ & $\mathrm{Se}$ & $\begin{array}{l}\text { Decocção e } \\
\text { torrado (em pó) }\end{array}$ & Depurativo & 0,19 & 8359 \\
\hline
\end{tabular}


TABELA 1. Lista de espécies medicinais indicadas pelos entrevistados do Distrito de Aratama no município de Assaré, Ceará, Brasil.

continuação...

\begin{tabular}{|c|c|c|c|c|c|c|c|c|}
\hline $\begin{array}{l}\text { Família e Nome } \\
\text { Científico }\end{array}$ & Nome Popular & ES & HB & $\begin{array}{c}\text { Parte } \\
\text { utilizada }\end{array}$ & Preparo & $\begin{array}{l}\text { Utilização/ } \\
\text { Indicação popular }\end{array}$ & IR & NH \\
\hline Sida cordifolia L. & Malva branca & Ex & $\mathrm{Ab}$ & $\mathrm{Ra}$ & $\begin{array}{l}\text { Decocção, } \\
\text { lambedor }\end{array}$ & $\begin{array}{l}\text { Inflamação, gripe, tosse, } \\
\text { garganta inflamada }\end{array}$ & 0,53 & $\mathrm{nc}$ \\
\hline \multicolumn{9}{|l|}{ Monimiaceae } \\
\hline Peumus boldus Mol. & Boldo & Ex & $\mathrm{Sb}$ & Fo & Decocção & $\begin{array}{l}\text { Labirintite, dor no estômago, } \\
\text { dor em geral, gripe, má } \\
\text { digestão, dor na barriga, } \\
\text { infecção no intestino, dor no } \\
\text { fígado }\end{array}$ & 1,25 & ncp \\
\hline \multicolumn{9}{|l|}{ Musaceae } \\
\hline Musa paradisiaca L. & Banana & Ex & $\mathrm{Ab}$ & La & $\begin{array}{l}\text { Látex com } \\
\text { água }\end{array}$ & $\begin{array}{l}\text { Ulcera, dor de dente, verruga, } \\
\text { gripe }\end{array}$ & 0,63 & $\mathrm{nc}$ \\
\hline \multicolumn{9}{|l|}{ Myrtaceae } \\
\hline $\begin{array}{l}\text { Eucalyptus globulus } \\
\text { Labill. }\end{array}$ & Eucalipto & Ex & $\mathrm{Ar}$ & Fo & $\begin{array}{l}\text { Decocção ou } \\
\text { infusão }\end{array}$ & $\begin{array}{l}\text { Febre, garganta inflamada, } \\
\text { asma, gripe, congestão nasal }\end{array}$ & 0,60 & ncp \\
\hline $\begin{array}{l}\text { Eugenia caryophyllus } \\
\text { Spreg. }\end{array}$ & Cravo-da- índia & Ex & $\mathrm{Ar}$ & $\begin{array}{l}\text { F I } \\
\text { (botões } \\
\text { florais) }\end{array}$ & Decocção & Cólica menstrual & 0,19 & $\mathrm{nc}$ \\
\hline $\begin{array}{l}\text { Eugenia Malaccensis } \\
\text { Linn. }\end{array}$ & Jambo & Ex & $\mathrm{Ar}$ & Cc & Decocção & Dor de dente & 0,19 & ncp \\
\hline Psidium guajava L. & Goiaba & Ex & $\mathrm{Ar}$ & $\begin{array}{l}\mathrm{F} \quad \mathrm{o} \\
\text { (broto) } \\
\text { e Fr }\end{array}$ & $\begin{array}{l}\text { Decocção, } \\
\text { infusão }\end{array}$ & Diarreia & 0,19 & 8348 \\
\hline \multicolumn{9}{|l|}{ Myristicaceae } \\
\hline Myristica fragrans Houtt. & Nós-moscada & Ex & $\mathrm{Ar}$ & $\mathrm{Fr}$ & $\begin{array}{l}\text { Decocção, } \\
\text { raspas com } \\
\text { água, de molho }\end{array}$ & $\begin{array}{l}\text { Gastura, dor em geral, dor } \\
\text { no estômago, cólica geral, } \\
\text { tontura, dor de cabeça, cólicas } \\
\text { menstruais }\end{array}$ & 1,12 & $\mathrm{nc}$ \\
\hline \multicolumn{9}{|l|}{ Nyctaginaceae } \\
\hline Boerhavia coccinea Willd. & Pega-pinto & Ex & $\mathrm{He}$ & $\mathrm{Ra}$ & Sumo & Inflamação & 0,19 & ncp \\
\hline \multicolumn{9}{|l|}{ Olacaceae } \\
\hline Ximenia americana L. & Ameixa & $\mathrm{Na}$ & $\mathrm{Ab}$ & $\begin{array}{l}\text { Fo, Cc } \\
\text { e Ec }\end{array}$ & $\begin{array}{l}\text { Decocção, } \\
\text { infusão, } \\
\text { de molho, } \\
\text { cataplasma, } \\
\text { casca torrada } \\
\text { (em pó) }\end{array}$ & $\begin{array}{l}\text { Inflamação uterina, garganta } \\
\text { inflamada, inflamação } \\
\text { ginecológica, ferimentos, } \\
\text { cicatrizante, inflamação, } \\
\text { cansaço }\end{array}$ & 1,12 & ncp \\
\hline \multicolumn{9}{|l|}{ Papaveraceae } \\
\hline Argemone mexicana L. & Carro-santo & Ex & $\mathrm{He}$ & $\mathrm{Ra}$ & Decocção & Bronquite & 0,19 & ncp \\
\hline \multicolumn{9}{|l|}{ Papilodaceae } \\
\hline $\begin{array}{l}\text { Adiantum capillus-veneris } \\
\text { L. }\end{array}$ & Avenca & Ex & $\mathrm{He}$ & Fo & Sumo & Angina no peito & 0,19 & $\mathrm{nc}$ \\
\hline Passifloraceae & & & & & & & & \\
\hline
\end{tabular}


TABELA 1. Lista de espécies medicinais indicadas pelos entrevistados do Distrito de Aratama no município de Assaré, Ceará, Brasil.

continuação...

\begin{tabular}{|c|c|c|c|c|c|c|c|c|}
\hline $\begin{array}{l}\text { Família e Nome } \\
\text { Científico }\end{array}$ & Nome Popular & ES & HB & $\begin{array}{c}\text { Parte } \\
\text { utilizada }\end{array}$ & Preparo & $\begin{array}{l}\text { Utilização/ } \\
\text { Indicação popular }\end{array}$ & IR & NH \\
\hline $\begin{array}{l}\text { Passiflora cincinnata } \\
\text { Mast. }\end{array}$ & Maracujá-do-mato & $\mathrm{Na}$ & $\mathrm{He}$ & Fo & Decocção & $\begin{array}{l}\text { Nervosismo, pressão alta, dor } \\
\text { de urina, calmante }\end{array}$ & 0,78 & 8342 \\
\hline \multicolumn{9}{|l|}{ Pedaliaceae } \\
\hline Sesamum indicum L. & Gergelim & Ex & $\mathrm{He}$ & $\mathrm{Se}$ & $\begin{array}{l}\text { Decocção } \\
\text { torrada, pilada } \\
\text { de molho, óleo }\end{array}$ & $\begin{array}{l}\text { Febre, afina o sangue, } \\
\text { inflamação, tônico capilar, } \\
\text { hematomas }\end{array}$ & 0,97 & 8351 \\
\hline \multicolumn{9}{|l|}{ Phyllanthaceae } \\
\hline $\begin{array}{l}\text { Phyllanthus amarus } \\
\text { Schumach. }\end{array}$ & Quebra-pedra & Ex & $\mathrm{He}$ & Ra e FI & Decocção & $\begin{array}{l}\text { Dor nos rins, dor no fígado, } \\
\text { pedras nos rins }\end{array}$ & 0,60 & ncp \\
\hline \multicolumn{9}{|l|}{ Piperaceae } \\
\hline Piper nigrum L. & Pimenta-do-reino & Ex & L & Fo & Sumo & Depurativo & 0,19 & nc \\
\hline \multicolumn{9}{|l|}{ Plantaginaceae } \\
\hline Plantago major L. & Transagem & $\mathrm{Na}$ & $\mathrm{He}$ & Se e Fo & $\begin{array}{l}\text { Lambedor, } \\
\text { Decocção }\end{array}$ & Inflamação, falta de ar & 0,39 & nc \\
\hline \multicolumn{9}{|l|}{ Poaceae } \\
\hline $\begin{array}{l}\text { Cymbopogon citratus } \\
\text { (D.C.) Stapf. }\end{array}$ & Capim-santo & Ex & $\mathrm{He}$ & Fo & Decocção & $\begin{array}{l}\text { Nervosismo, gripe, calmante, } \\
\text { pressão alta, falta de apetite }\end{array}$ & 0,97 & $\mathrm{nc}$ \\
\hline Saccharum officinarum L. & $\begin{array}{l}\text { Cana-de-açúcar- } \\
\text { roxa }\end{array}$ & Ex & $\mathrm{He}$ & Fo & Decocção & $\begin{array}{l}\text { Pressão alta, inchaço, } \\
\text { problemas oftalmológicos }\end{array}$ & 0,46 & nc \\
\hline Zea mays L. & Milho-roxo & Ex & $\mathrm{He}$ & Et & Decocção & $\begin{array}{l}\text { Dor de barriga, Vômito, Má } \\
\text { digestão }\end{array}$ & 0,33 & 8350 \\
\hline \multicolumn{9}{|l|}{ Polygalaceae } \\
\hline $\begin{array}{l}\text { Bredemeyera brevifolia } \\
\text { Klotzk. }\end{array}$ & Laça-vaqueiro & $\mathrm{Na}$ & $\mathrm{He}$ & $\mathrm{Ra}$ & Decocção & Dores reumáticas & 0,19 & ncp \\
\hline \multicolumn{9}{|l|}{ Punicaceae } \\
\hline Punica granatum $\mathrm{L}$. & Romã & Ex & $A b$ & $\begin{array}{l}\text { Fo, Cf } \\
\text { e Se }\end{array}$ & $\begin{array}{l}\text { Decocção } \\
\text { ou infusão, } \\
\text { cataplasma, } \\
\text { sumo das } \\
\text { sementes e } \\
\text { lambedor }\end{array}$ & $\begin{array}{l}\text { Gastrite, garganta inflamada, } \\
\text { tosse }\end{array}$ & 0,46 & 8913 \\
\hline \multicolumn{9}{|l|}{ Rhamnaceae } \\
\hline Ziziphus joazeiro Mart. & Juazeiro & $\mathrm{Na}$ & $\mathrm{Ar}$ & $\begin{array}{l}\text { Fo, Fr, } \\
\text { Cc e Ec }\end{array}$ & $\begin{array}{l}\text { Decocção, } \\
\text { infusão, raspas } \\
\text { do caule de } \\
\text { molho }\end{array}$ & $\begin{array}{l}\text { Problemas no Fígado, caspas, } \\
\text { tônico capilar }\end{array}$ & 0,51 & 8346 \\
\hline \multicolumn{9}{|l|}{ Rubiaceae } \\
\hline Coffea arabica L. & Café & Ex & $\mathrm{Ab}$ & $\mathrm{Se}$ & $\begin{array}{l}\text { Torrado (em } \\
\text { pó) }\end{array}$ & Garganta inflamada & 0,19 & ncp \\
\hline $\begin{array}{l}\text { Coutarea hexandra } \\
\text { (Jacq.) K. Schum. }\end{array}$ & Quina-quina & $\mathrm{Na}$ & $\mathrm{Ar}$ & $\begin{array}{l}\mathrm{Ra}, \mathrm{Cc} \\
\mathrm{e} \mathrm{Ec}\end{array}$ & $\begin{array}{l}\text { Decocção ou } \\
\text { infusão }\end{array}$ & febre, inflamação no nariz & 0,39 & $\mathrm{nc}$ \\
\hline Genipa americana L. & Genipapo & $\mathrm{Na}$ & $\operatorname{Ar}$ & Fr e Cc & Decocção & Fraturas & 0,19 & ncp \\
\hline
\end{tabular}


TABELA 1. Lista de espécies medicinais indicadas pelos entrevistados do Distrito de Aratama no município de Assaré, Ceará, Brasil.

continuação...

\begin{tabular}{|c|c|c|c|c|c|c|c|c|}
\hline $\begin{array}{l}\text { Família e Nome } \\
\text { Científico }\end{array}$ & Nome Popular & ES & HB & $\begin{array}{c}\text { Parte } \\
\text { utilizada }\end{array}$ & Preparo & $\begin{array}{l}\text { Utilização/ } \\
\text { Indicação popular }\end{array}$ & IR & NH \\
\hline \multicolumn{9}{|l|}{ Rutaceae } \\
\hline $\begin{array}{l}\text { Citrus aurantifolia } \\
\text { (Christm.) Swingle }\end{array}$ & Limão & Ex & $\mathrm{Ar}$ & $\mathrm{Fr}$ & $\begin{array}{l}\text { Decocção, } \\
\text { lambedor, } \\
\text { Suco, sumo }\end{array}$ & $\begin{array}{l}\text { Gripe, garganta inflamada, } \\
\text { febre, caspas }\end{array}$ & 0,60 & 8353 \\
\hline Citrus sinensis Osbeck. & Laranja & Ex & $\mathrm{Ar}$ & $\begin{array}{l}\text { Fo, Cc } \\
\text { e Cf }\end{array}$ & $\begin{array}{l}\text { Decocção, } \\
\text { infusão, de } \\
\text { molho, sumo } \\
\text { da casca do } \\
\text { fruto, lambedor }\end{array}$ & $\begin{array}{l}\text { Gripe, garganta inflamada, } \\
\text { intestino preso, dor no } \\
\text { estômago, calmante, febre, } \\
\text { gastura, má digestão }\end{array}$ & 1,00 & ncp \\
\hline Citrus reticulata $\mathrm{B}$. & Tangerina & Ex & $\mathrm{Ar}$ & $\mathrm{Cf}$ & Decocção & Colesterol alto, labirintite & 0,39 & ncp \\
\hline Ruta graveolens L. & Arruda & Ex & $\mathrm{He}$ & Fo & $\begin{array}{l}\text { Decocção, } \\
\text { Infusão, Sumo }\end{array}$ & $\begin{array}{l}\text { Cólica menstrual, dor de } \\
\text { ouvido, dores em geral, } \\
\text { cólicas }\end{array}$ & 0,59 & $\mathrm{nc}$ \\
\hline \multicolumn{9}{|l|}{ Scrophulariaceae } \\
\hline Scoparia dulcis L. & Vassourinha & $\mathrm{Na}$ & $\mathrm{He}$ & Fo e Ra & Decocção & Infecção urinária & 0,19 & 8368 \\
\hline \multicolumn{9}{|l|}{ Solanaceae } \\
\hline Solanum sp. & Melão-da-praia & $\mathrm{Na}$ & $\mathrm{He}$ & $\mathrm{Fr}$ & Lambedor & Problemas oftalmológicos & 0,19 & $\mathrm{nc}$ \\
\hline Solanum tuberosum L. & Batata inglesa & Ex & $A b$ & $\mathrm{Ra}$ & Sumo & Gastrite, enxaqueca & 0,39 & $\mathrm{nc}$ \\
\hline Solanum paniculatum L. & Jurubeba & $\mathrm{Na}$ & $\mathrm{Ar}$ & Fo & Decocção & Dor no fígado & 0,19 & 8336 \\
\hline Solanum melongena $\underline{\text { L. }}$ & Berinjela & Ex & $\mathrm{He}$ & Fo & De molho & Colesterol alto & 0,19 & nc \\
\hline Solanum lycopersicum L. & Tomate & Ex & $\mathrm{He}$ & Fo & Sumo & Problemas oftalmológicos & 0,19 & ncp \\
\hline \multicolumn{9}{|l|}{ Sterculiaceae } \\
\hline Waltheria indica L. & Malva-do-reino & Ex & $\mathrm{He}$ & Fo & Lambedor & $\begin{array}{l}\text { Garganta inflamada, gripe, dor } \\
\text { de cabeça, tosse, inflamação, } \\
\text { dor de estômago }\end{array}$ & 1,19 & 8357 \\
\hline \multicolumn{9}{|l|}{ Turneraceae } \\
\hline Turnera ulmifolia L. & Chanana & $\mathrm{Na}$ & $\mathrm{He}$ & $\mathrm{Ra}$ & Decocção & Inflamação em geral & 0,19 & ncp \\
\hline \multicolumn{9}{|l|}{ Verbenaceae } \\
\hline $\begin{array}{l}\text { Lippia alba (Mill.) N. E. Br. } \\
\text { Ex Britton } \\
\text { \& P. Wilson }\end{array}$ & Erva Cidreira & Ex & $\mathrm{Sb}$ & Fo e Se & $\begin{array}{l}\text { Decocção } \\
\text { e infusão }\end{array}$ & $\begin{array}{l}\text { Calmante, pressão alta, falta } \\
\text { de apetite, nervos, gripe, } \\
\text { enxaqueca, gastura }\end{array}$ & 1,17 & 8369 \\
\hline \multicolumn{9}{|l|}{ Violaceae } \\
\hline $\begin{array}{l}\text { Hybanthus calceolaria (L.) } \\
\text { Oken. }\end{array}$ & Pepaconha & $\mathrm{Na}$ & $\mathrm{He}$ & $\mathrm{Ra}$ & Decocção & $\begin{array}{l}\text { Nascimento de dente em } \\
\text { crianças, dor de dente }\end{array}$ & 0,26 & $\mathrm{ncp}$ \\
\hline \multicolumn{9}{|l|}{ Zingiberaceae } \\
\hline Zingiber officinalis Rosc. & Gengibre & Ex & $\mathrm{He}$ & $\mathrm{Ra}$ & $\begin{array}{l}\text { Decocção, de } \\
\text { molho }\end{array}$ & Dor em geral, cólica, tontura & 0,46 & $\mathrm{nc}$ \\
\hline
\end{tabular}

LEGENDA: Na: nativas; Ex: exótica; Ar: arbóreo; Ab: Arbustivo; Sb: subarbustivo; He: Herbáceo; L: liana; IR: importância relativa; Fo: folhas, FI: flor, Ra: raiz, Rat: raiz-tubérculo; Se: semente, Cc: casca do caule, Ec: entrecasca do caule; Fr: fruto; Cf: casca do fruto; La: látex; Et: estigma; ES: Estado da planta; HB: Hábito da planta; NH: Número de Herbário; ncp: numero de coleção em processo no Herbário; nc: não coletada; 
A espécie com maior IR foi a Mentha spicata L. (IR 2,00), seguida da Rosmarinus officinalis L. (IR 1,51) e de Allium sativum L. (IR 1,32 ), as quais se tratam de plantas exóticas que estão geralmente presentes em quintais domiciliares ou são adquiridas por terceiros. A espécie Mentha spicata, que apresentou o maior número de sistemas corporais (oito) e o maior número de propriedades atribuídas (14), está entre as 71 plantas de interesse medicinal do SUS (Brasil, 2009). Em testes farmacológicos observou-se que esta espécie traz benefícios ao tratamento de hipertensão arterial e age na diminuição dos níveis de colesterol (Barbalho et al., 2011). Isto vai de encontro com algumas das informações obtidas na comunidade sobre o uso medicinal desta planta, que é utilizada para colesterol alto, problemas no coração, derrame, entre outros.

Em relação às espécies nativas, a que apresentou maior IR foi Bauhinia cheilantha (Bong.) (IR 1,29), com seis sistemas corporais e seis propriedades de uso, seguida de Ximenea americana L., (IR 1,12), com quatro sistemas corporais e sete propriedades de uso. Nas análises de Silva \& Filho (2002) a espécie $B$. cheilantha apresentou efeito hipoglicemiante, o que condiz com sua citação na comunidade. No estudo de Brasileiro et al. (2008) $X$. americana apresenta importantes compostos, principalmente os taninos, que funcionam como agente anti-inflamatório no sistema humano, confirmando o grande número de citações de uso da espécie como anti-inflamatório em diferentes sistemas corporais neste levantamento.

Em levantamentos realizados na Caatinga observa-se que algumas espécies variam em relação a sua importância relativa. $B$. cheilantha em trabalho realizado por Albuquerque et al., (2007a) apresentou IR 1,70, no Ceará, no trabalho de Cartaxo et al., (2010) obteve IR de 1,40 e, na região do Xingó, apresentou IR de 1,33 (Almeida at al., 2006) mostrando índices de versatilidade maiores que 1. O mesmo aconteceu com a espécie $X$. americana que apresentou IR 1,12 neste estudo, no trabalho de Oliveira et al., (2010b) IR de 1,79, e IR de 0,19 no levantamento de Albuquerque et al (2007b). Esta variação, de modo geral, pode estar relacionada aos diferentes tipos de doenças e sistemas corporais que uma determinada comunidade tem necessidade de tratar. Muitas vezes uma mesma planta é utilizada para tratar vários tipos de doenças e/ou sintomas em uma comunidade, mas em outra, é quase desconhecida por suas propriedades.

Concordância de Uso das Espécies Medicinais As espécies medicinais foram indicadas para tratamento de 84 finalidades terapêuticas e foram classificadas em 16 categorias de sistemas corporais (Tabela 2). Dentre as categorias citadas, apenas a de Doenças Infecciosas e Parasitárias (DIP) não obteve consenso entre os informantes, apresentando valor zero; situação semelhante também pode ser observada em outras pesquisas realizadas no semiárido Nordestino (Almeida \& Albuquerque, 2002; Cartaxo et al., 2010; Souza, 2012). As demais categorias apresentaram valores que variaram de 0,2 a 0,7 mostrando concordância entre os informantes, mesmo não apresentando o valor máximo de 1.

Os maiores valores do Fator do Consenso de Informante $(\mathrm{FCl})$ foram relacionados às categorias de Desordens mentais e comportamentais (DMC), Afecções ou dores não definidas (ADND), Transtorno do sistema respiratório (TSR), Doenças de pele e tecido celular subcutâneo (DPTCS) e Transtorno do sistema sensorial ouvidos (TSS(OU)), todas com $\mathrm{FCl}$ de 0,7 .

A categoria DMC foi relacionada com nove espécies e 31 citações de uso para calmante. O seu alto valor neste estudo chega a ser incomum quando comparado a outros levantamentos realizados no semiárido, onde esta categoria é pouco referenciada e/ou apresenta valores considerados baixos (Almeida \& Albuquerque 2002; Almeida et al., 2006; Cartaxo et al., 2010). Lippia alba (Mill), recebeu o maior numero de citações (11) para esta categoria, sendo utilizada suas folhas e sementes na forma de decocção. Em relação as suas atividades farmacológicas, segundo Mattos et al. (2007), a espécie apresenta propriedades como calmante e ansiolítica, o que coincide com as citações de uso neste trabalho. Em seguida, para esta categoria, foram citadas Cymbopogon citratus, que apresentou dez citações, Citrus sinensis Osbeck., com quatro, e Rosmarinus officinalis L. com duas citações, sendo indicadas para calmante e problemas relacionados ao nervosismo.

Em relação ao número de usos reportados, ADND, apresentou o segundo maior número de citações (127), correspondendo a $18,75 \%$, e o maior número de espécies de plantas (42), o que demonstra o amplo conhecimento de espécies medicinais dentro da comunidade relacionadas com o tratamento dos problemas de saúde que, a princípio, não tem causa definida, tais como febre e inflamações em geral. Nesta categoria, Eucalyptus globulus recebeu onze citações para febre, seguida de Mentha spicata, com seis. Para inflamação, Myracrodruon urundeuva sobressai com treze citações, o que confirma a importância desta espécie sobre seu conhecimento e utilização, além de estudos que demonstram o seu potencial no tratamento de diversas manifestações inflamatórias e bacterianas (Souza et al., 2007; Botelho et al.,

Rev. Bras. PI. Med., Campinas, v.16, n.4, p.912-930, 2014. 
TABELA 2. Fator de Consenso de Informantes com base nas citações de uso das espécies medicinais pelos informantes do Distrito de Aratama no município de Assaré, Ceará, Brasil.

\begin{tabular}{|c|c|c|c|}
\hline Categorias & $\begin{array}{l}\mathrm{N}^{\circ} \text { de } \\
\text { usos }\end{array}$ & $\mathrm{N}^{\circ}$ e espécies de plantas & $\mathrm{FCl}$ \\
\hline DMC: Calmante & 31 & $\begin{array}{l}9 \text { - Alecrim, Canela, Capim Santo, Endro, Erva Cidreira, Hortelã, } \\
\text { Laranja, Maracujá do Mato, Marcela }\end{array}$ & 0,7 \\
\hline $\begin{array}{l}\text { ADND: Dores em geral, febre, } \\
\text { cólicas, Inflamação em geral, } \\
\text { hemorragia em geral }\end{array}$ & 127 & $\begin{array}{l}42 \text {-Alecrim, Alfavaca, Alho, Ameixa, Anador, Angico, Aroeira, Arruda, } \\
\text { Babosa, Barbatimão, Boldo, Cajú, Chanana, Eucalipto, Feijão, Frei } \\
\text { Jorge, Gengibre, Gergelim, Girassol, Graviola, Hortelã, Imbiriba, } \\
\text { Imburana, Imburana de Cheiro, Janaguba, Laranja, Limão, Losna, } \\
\text { Macaúba, Malva Sete Dores, Malva Branca, Malva Corona, Malva do } \\
\text { Reino, Marcela, Marmeleiro, Mororó, Muçambê, Noz-Moscada, Pau } \\
\text { d'arco-Roxo, Pega Pinto, Pluma, Quina-Quina, Transagem, Velame }\end{array}$ & 0,7 \\
\hline $\begin{array}{l}\text { TSR: Tosse, Rouquidão, gripe, } \\
\text { estalecido, garganta inflamada, } \\
\text { bronquite, sinusite, asma, } \\
\text { congestão nasal, nariz inflamado, } \\
\text { falta de ar, cansaço }\end{array}$ & 129 & $\begin{array}{l}41 \text { - Abacaxi; Agrião, Alecrim, Alfavaca, Alho, Ameixa, Angico, } \\
\text { Aroeira, Babosa, Balsamo, Banana, Boldo, Café, Capim Santo, } \\
\text { Carro Santo, Cebola Branca, Erva Cidreira, Eucalipto, Frei Jorge, } \\
\text { Hortelã, Imburana, Imburana de Cheiro, Jatobá, Laranja, Limão, } \\
\text { Macaúba, Malva Branca, Malva Corona, Malva do Reino, Mamão, } \\
\text { Mamona, Manjericão, Mororó, Muçambê, Pau d'arco-Roxo, Pequi, } \\
\text { Quebra-Faca, Quina-Quina, Romã, Transagem, Urucum }\end{array}$ & 0,7 \\
\hline DPTCS: Tônico capilar, caspas & 12 & 5 - Babosa, Gergelim, Juazeiro, Limão, Mamona & 0,7 \\
\hline $\begin{array}{l}\text { TSS (OU): Dor de ouvido, } \\
\text { labirintite }\end{array}$ & 21 & 6 - Agrião, Arruda, Boa Noite, Boldo, Manjericão, Tangirina & 0,7 \\
\hline $\begin{array}{l}\text { TSN: Dor de cabeça, enxaqueca, } \\
\text { problemas nos nervos, tontura, } \\
\text { epilepsia, Acidente Vascular } \\
\text { Cerebral }\end{array}$ & 47 & $\begin{array}{l}17 \text { - Alecrim, Alho, Anador, Batata Inglesa, Camomila, Capim Santo, } \\
\text { Erva Cidreira, Gengibre, Girassol, Hortelã, Imburana de Cheiro, } \\
\text { Malva do Reino, Maracujá do Mato, Mororó, Mostarda, Noz-Moscada, } \\
\text { Quebra-Faca }\end{array}$ & 0,6 \\
\hline $\begin{array}{l}\text { TSG: Inflamação uterina, } \\
\text { inflamação ginecológica, } \\
\text { inflamação do ovário, cólica } \\
\text { menstrual, Corrimento, dor } \\
\text { ginecológica, infecção urinária, } \\
\text { dor nos rins, pedras nos rins, } \\
\text { problemas nos rins }\end{array}$ & 58 & $\begin{array}{l}22 \text { - Abacate, Ameixa, Aroeira, Arruda, Cajú, Castanhola, Chapéu de } \\
\text { Couro, Coco, Cravo, Crista de Galo, Espinho de Agulha, Frei Jorge, } \\
\text { Hortelã, Imbu, Jurema Preta, Losna, Malva Sete Dores, Maracujá do } \\
\text { Mato, Mororó, Noz-Moscada, Quebra-Pedra, Vassourinha }\end{array}$ & 0,6 \\
\hline $\begin{array}{l}\text { TSD: Inflamações na boca, } \\
\text { gastrite, úlcera, dor de dente, } \\
\text { dente inflamado, dorno estômago, } \\
\text { má digestão, diarreia, gastura, } \\
\text { Vômito, intestino preso, dor no } \\
\text { intestino, desinteria, nascimento } \\
\text { de dente, dor de barriga }\end{array}$ & 101 & $\begin{array}{l}42 \text { - Abacate, Agrião, Alecrim, Algaroba, Balsamo, Banana, Batata } \\
\text { Doce, Batata Inglesa, Boldo, Braúna, Coentro, Endro, Erva Cidreira, } \\
\text { Erva Doce, Girassol, Goiaba, Hortelã, Imbiriba, Jambo, Jerimum } \\
\text { Jurema Preta, Laranja, Malva Sete Dores, Malva Corona, Malva } \\
\text { do Reino, Mamão, Mandacarú, Mandioca, Marcela, Marmeleito, } \\
\text { Melancia, Milho-roxo, Mostarda, Mulungu, Noz-Moscada, Palma, } \\
\text { Papaconha, Pau d'arco-Roxo, Pinha, Romã, Sabugueiro, Siriguela }\end{array}$ & 0,6 \\
\hline DSOH: Dores no fígado, anemia & 18 & $\begin{array}{l}8 \text { - Boldo, Braúna Carqueja, Jatobá, Juazeiro, Jurubeba, Marcela, } \\
\text { Quebra-Pedra }\end{array}$ & 0,6 \\
\hline
\end{tabular}


TABELA 2. Fator de Consenso de Informantes com base nas citações de uso das espécies medicinais pelos informantes do Distrito de Aratama no município de Assaré, Ceará, Brasil.

\begin{tabular}{|c|c|c|c|}
\hline Categorias & $\begin{array}{l}\mathrm{N}^{\circ} \text { de } \\
\text { usos }\end{array}$ & $\mathrm{N}^{\circ}$ e espécies de plantas & $\mathrm{FCl}$ \\
\hline $\begin{array}{l}\text { DSOTC: Dores reumáticas, dor } \\
\text { nas pernas, Dor na coluna }\end{array}$ & 11 & 5 - Alecrim, Laça Vaqueiro, Marcela, Pau-Ferro, Unha de Gato & 0,6 \\
\hline $\begin{array}{l}\text { TSC: Doenças do coração, } \\
\text { trombose, pressão alta, angina } \\
\text { no peito, afina o sangue, } \\
\text { hemorroidas, inchaço, derrame }\end{array}$ & 37 & $\begin{array}{l}18 \text { - Alecrim, Alho, Avenca, Babosa, cana-de-açúcar roxa, Canela, } \\
\text { Capim Santo, Endro, Erva Cidreira, Gergelim, Girassol, Graviola, } \\
\text { Hortelã, Ingazeira, Jatobá, Maracujá do Mato, Mostarda, Patchulê }\end{array}$ & 0,5 \\
\hline $\begin{array}{l}\text { LEOCCE: Depurativo, ferimentos, } \\
\text { cicatrizante, queimaduras, } \\
\text { verrugas, hematomas, pancadas }\end{array}$ & 23 & $\begin{array}{l}13 \text { - Algodão-brabo, Ameixa, Aroeira, Banana, Cajú, Feijão, } \\
\text { Gergelim, Girassol, Genipapo, Jurema Preta, Malva Corona, Pequi, } \\
\text { Pimenta malagueta }\end{array}$ & 0,5 \\
\hline N: Câncer & 5 & 3 - Alho, Babosa, Pau d'arco-Roxo & 0,5 \\
\hline $\begin{array}{l}\text { DGENM: Emagrecer, colesterol } \\
\text { alto, falta de apetite, fraqueza, } \\
\text { diabetes }\end{array}$ & 14 & $\begin{array}{l}8 \text { - Alho, Berinjela, Capim Santo, Erva Cidreira, Graviola, Hortelã, } \\
\text { Mororó, Tangirina }\end{array}$ & 0,5 \\
\hline $\begin{array}{l}\text { TSS (OLH): ramo no olho, } \\
\text { conjuntivite, problemas } \\
\text { oftalmológicos, olho inflamado }\end{array}$ & 5 & 4 - cana-de-açúcar roxa, Manjericão, Melão da Praia, Tomate & 0,2 \\
\hline DIP: Infecção no intestino & 1 & 1 - Boldo & 0 \\
\hline
\end{tabular}

LEGENDA: ADND: Afecções ou dores não definidas; DGEMN: Doença das Glândulas Endócrinas, da nutrição e do metabolismo; DIP: Doenças infecciosas e parasitárias; DMC: Desordens mentais e comportamentais; DSOH: Doenças do sangue e órgão hematopoiéticos; DSOTC: Doença do tecido osteomuscular e tecido conjuntivo; LEOCCE: lesões, envenenamentos e outras consequências externas; N: Neoplasias; TSD: Transtorno do Sistema Digestório; Transtorno do Sistema Geniturinário; TSN: Transtorno do sistema nervoso; TSR: Transtorno do Sistema Respiratório; TSS(O): Transtorno do sistema sensorial (ouvidos); TSS(OLH): Transtorno do sistema sensorial (olhos); TSC: Transtorno do sistema circulatório; DPTCS: Doenças de pele e tecido celular subcutâneo.

2008; Sá et al., 2009a; Lucena et al., 2011).

Transtorno do Sistema Respiratório (TSR) foi a categoria que mais obteve números de citações de usos (129), o que corresponde a $20,15 \%$ do total de citações (640), obtendo o segundo maior número de espécies indicadas (41), 35,34\% do total de espécies. Esse alto número demostra o amplo conhecimento da comunidade em relação às plantas medicinais que tratam os problemas respiratórios. Em estudos realizados em áreas semiáridas do Nordeste por Almeida et al. (2006), Cartaxo et al. (2010) e Souza (2012) transtornos do sistema respiratório também faz parte das categorias mais frequentemente citadas, mostrando elevada concordância de uso.

A espécie que atingiu maior número de citações para problemas respiratórios (gripe, tosse, e garganta inflamada) foi Plectranthus barbatus com 16 citações, que é geralmente preparada na forma de lambedor. Amburana cearensis, Mentha spicata, Anadenanthera colubrina, Citrus aurantifolia, Eucalyptus globulus, e Punica granatum, também foram comumente indicadas para o tratamento de problemas respiratórios, sendo utilizadas para tosse, asma, gripe, rouquidão, coriza e congestão nasal. $P$. amboinicus no estudo de Nogueira et al. (2008) apresentou atividade antimicrobiana, sendo eficaz contra enfermidades que acometem o sistema respiratório (garganta inflamada). Em relação à espécie nativa dentro desta categoria, $A$. cearensis, endêmica do ecossistema de caatinga, foi citada para o tratamento de gripe e inflamações, o que coincide com o estudo de Leal et al., (2008), no qual demonstra que a casca do caule desta espécie tem atividade broncodilatadora e anti-inflamatória.

Doenças de Pele e do Tecido Celular Subcutâneo (DPTCS) estiveram relacionadas com a espécie Ziziphus joazeiro sendo a mais utilizada para caspa e tratamento capilar. Cartaxo et al., (2010), mencionou DPTCS como sendo a categoria com maior índice de concordância de uso, tendo esta mesma espécie como representativa. Estudos pré-clínicos que avaliaram as propriedades da casca e das folhas de $Z$. joazeiro, comprovaram que a espécie possui atividade antibacteriana e antifúngica, principalmente nos tecidos cutâneo e 
subcutâneo (Cruz et al., 2007; Alviano et al., 2008) o que corrobora com a utilização popular desta espécie.

Transtorno do Sistema Sensorial Ouvidos (TSS(OU)), teve a Ruta graveolens como sendo a espécie principal na categoria, apresentando doze citações para dor no ouvido, seguida do Ocimum basilicum L. que apresentou cinco citações, para tratamento desta enfermidade; nas duas espécies são utilizadas o sumo das folhas aplicados diretamente no ouvido. A folhas da $R$. graveolens também são utilizadas para preparo de chá por decocção ou infusão quando administradas para diminuição de cólicas menstruais. Em estudos realizados com o extrato de $R$. graveolens contatouse que ela possui efeito anti-inflamatória (Raghav et al., 2006) e efeito antinociceptivo (Atta \& Alkofabi, 1998), esses efeitos comprovam a sua utilização pela comunidade no alivio de dores.

Para Transtorno do Sistema Digestório (TSD), 101 usos foram citados para problemas relacionados ao trato digestivo e dentes. Esta categoria apresentou 42 espécies indicadas para tratar problemas relacionados à má digestão, dores estomacais, e dores de barriga. Egletes viscosa foi a mais indicada para estes problemas, tendo como preparo, a imersão das sementes em água, onde ficam "de molho" para sua ingestão. Pneumus boldus foi o segundo mais citado, sendo utilizado na forma de chá por decocção das folhas, principalmente para tratar ou aliviar dores estomacais.

Com 58 citações, o Transtorno do Sistema Genitourinário (TSG) compreendeu 22 espécies e obteve índice de concordância de 0,6. As espécies Myracrodruon urundeuva e Ximenea americana, juntas, apresentaram 14 citações para tratar a inflamação ginecológica. Bauhinia cheilantha e Phyllanthus amarus foram as mais representativas para dor nos rins e afecções urinárias (8); as demais espécies abrangeram o restante das enfermidades relacionadas a este sistema. Muitas delas estiveram entre as mais citadas nos estudos de Albuquerque et al. (2007a) e Cartaxo et al. (2010), que aparecem como nativas, e são as mais conhecidas pelas populações do semiárido (Souza 2012).

As Doenças do Sangue e Órgão Hematopoiéticos (DSOH), Doença do Tecido Osteomuscular e Tecido Conjuntivo (DSOTC) e Transtornos do Sistema Nervoso (TSN) apresentaram $\mathrm{FCl}$ 0,6. Para DSOH Schinopsis brasiliensis foi a mais citada para dores no fígado. DSOTC recebeu 11 citações de usos $(9,48 \%)$ e cinco espécies citadas (4,31\%), tendo as espécies como Bredemeyera brevifolia e Acacia paniculata indicadas para dores na coluna e reumatismo, apresentando maior consenso entre os informantes nos cuidados para esse fim. As duas categorias apresentaram, em sua maioria, plantas nativas da caatinga. Estas informações populares são importantes na investigação de plantas medicinais nativas, uma vez que mais esforços podem ser fornecidos para o ecossistema e estudos mais específicos possam vir a descobrir importantes compostos medicinais para o surgimento de novas drogas eficazes. TSN teve a espécie Mentha spicata como a mais importante relativa a este sistema e a mais indicada dentro desta categoria, com 10 indicações para dor de cabeça e 1 para Acidente Vascular Cerebral.

Nas categorias de Doença das Glândulas Endócrinas, da Nutrição, e do Metabolismo (DGENM), Lesões, Envenenamentos, e outras Consequências Externas (LEOCCE), Transtorno do Sistema Circulatório (TSC) e Neoplasias (N) o índice de concordância foi o mesmo $(0,5)$. Com indicações de usos que variaram de 5 a 37 , os quais estiveram relacionados à três e 18 espécies. DGENM obteve o total de 14 indicações de uso para oito espécies, sendo que as citações mais frequentes foram para falta de apetite, que obteve seis citações para Lippia alba. Vinte e três indicações de uso e 13 espécies foram mencionadas para a categoria LEOCCE. Ferimento e cicatrizante foram os problemas que mais se destacaram, principalmente para as espécies Ximenea americana, Chenopodium ambrosioides e Anacardium occidentale, que, juntas, apresentaram 10 indicações para as doenças citadas. De acordo com Almeida et al., (2005) em estudos realizados na Caatinga nordestina, Ximenea americana e Anacardium occidentale são comumente indicadas para cicatrização e ferimentos. Para TSC Mentha spicata e Cymbopogon citratus, foram mencionadas para o tratamento de problemas do coração, derrame, trombose e pressão alta, sendo usadas na forma de chá por decocção.

Transtorno do Sistema Sensorial (Olhos) (TSS(OLH)) apresentaram fator de consenso baixo $(0,2)$, o que significa que o número de citações foi quase igual ao número de espécies indicadas, apresentando cinco usos e quatro espécies com porcentagem referente a $4,31 \%$ e $3,44 \%$ respectivamente. Nesta categoria, valores muito baixos são comuns em outros levantamentos, fato que pode ser justificado pela pouca citação de plantas que ajudem a sanar problemas relacionados ao sistema sensorial (olhos) (Almeida et al., 2006; Albuquerque et al., 2007a; Cartaxo et al., 2010; Souza, 2012).

Para Doenças Infecciosas e Parasitárias (DIP), verminoses, tétano e infecções intestinais são exemplos de doenças comuns a essa categoria. $\mathrm{O} \mathrm{FCl}$ foi de zero, significando que não houve concordância quanto ao uso de nenhuma espécie na localidade para esta finalidade. A categoria 
apresentou uma única indicação de uso (infecção no intestino) referente à espécie indicada (Pneumus boldus), o que pode mostrar que a procura da população para sanar problemas relacionados a esta categoria, é muito pouca ou até mesmo inexistente.

Poucas espécies nativas estiveram incluídas nos sistemas corporais que apresentaram altos valores de concordância, entretanto, Bauhinia cheilantha e Ximenia americana estiveram presentes em várias categorias, sendo utilizadas de forma consensual no tratamento de alguns dos sistemas corporais específicos. Os valores mais altos relacionados às categorias de sistemas corporais indicam que as espécies de plantas são culturalmente importantes para a comunidade estudada e são utilizadas, em sua maioria, consensualmente (Almeida \& Albuquerque, 2002; Almeida et al., 2006; Albuquerque et al., 2007b; Roque et al., 2010).

\section{CONCLUSÃO}

O estudo etnobotânico na comunidade de Aratama apresentou um notável conhecimento e/ou uso das propriedades terapêuticas das espécies e, embora o número de plantas medicinais exóticas tenha sido elevado, as espécies nativas como Bauhinia cheilantha e Ximenia americana se destacaram e podem ser promissoras em estudos de bioprospecção. O FCl foi representativo com apenas uma categoria com valor mínimo, o que mostra uma importante transmissão de informações sobre as espécies medicinais dentro da comunidade. Dentre todas as plantas citadas, a maioria demonstra uma ampla potencialidade medicinal, embora ainda possuam poucas comprovações de suas atividades biológicas.

Nessa perspectiva, considera-se que este estudo pode contribuir para posteriores trabalhos relacionado às praticas de uso das plantas medicinais, como também, que as informações fornecidas são essenciais para orientação e consolidação das propriedades terapêuticas presentes nas espécies.

\section{REFERÊNCIA}

AGRA, M.F.; G.S. BARACHO.; NURIT, K.; BASÍILIO, I.J.L.D.; COELHO, V.P.M. Medicinal and poisonous diversity of the flora of "Cariri Paraibano", Brazil. Journal of Ethnopharmacology. v.111, p.383-395, 2007.

ALBUQUERQUE, U.P; OLIVEIRA, R.F. Is the use-impact on native caatinga species in Brazil reduced by the high species richness of medicinal plants? Journal of Ethnopharmacology, v. 113, p.156-170, 2007.

ALBUQUERQUE, U.P. \& HANAZAKI, N. As pesquisas etnodirigidas na descoberta de novos fármacos de interesse médico e farmacêutico: fragilidades e perspectivas. Revista Brasileira de Farmacognosia. n.16, p.678-689. 2006.

ALBUQUERQUE, U.P. Implications of ethnobotanical studies on bioprospecting strategies of new drugs in semi-arid regions. The Open Complementary Medicine Journal, v. 2, p. 21-23, 2010.

ALBUQUERQUE, U.P. Re-examining hypotheses concerning the use and knowledge of medicinal plants: a study in the caatinga vegetation of NE Brazil. Journal of Ethnobiology and Ethnomedicine, v. 2, n.30, p.110, 2006.

ALBUQUERQUE, U.P.; HANAZAKI, N.; SOLDATI, G.T. Produtos florestais não-madeireiros: uma visão geral. In: SOLDATI, G.T.; ALBUQUERQUE, U.P. Árvores de valor e valor das árvores: pontos de conexão. Recife: NUPEEA. 2010a. p.17-59.

ALBUQUERQUE, U.P.; LUCENA, R.F.P.; ALENCAR, N. L. Métodos e técnicas para a coleta de dados etnobiológicos. In: Métodos e Técnicas na Pesquisa Etnobiológica e Etnoecológica, U. P. de Albuquerque, R. F. P. Lucena, and L. V. F. C. Cunha, Eds., NUPEEA, Recife, Brazil, 2010b, p.39-64.

ALBUQUERQUE, U.P.; LUCENA, R.F.P.; ALENCAR, N.L. Métodos e técnicas para coleta de dados etnobotânicos. In: ALBUQUERQUE, U.P., LUCENA, R.F.P., CUNHA, L.V.F.C. (Orgs), Métodos e técnicas na pesquisa etnobotânica. COMUNIGRAF, Recife, 2008. p. 41-72.

ALBUQUERQUE, U.P; LUCENA, R.F.P. Métodos e técnicas para a coleta de dados. In: ALBUQUERQUE, U.P; LUCENA, R.F.P. Métodos e técnicas na pesquisa etnobotânica. Recife: Editora LivroRápido/ Nupeea, 2004, p. 37-62.

ALBUQUERQUE, U.P; MEDEIROS, P.M.; ALMEIDA, A.L.; MONTEIRO, J.M.; LINS NETO, E.M.F.; MELO, J.G.; SANTOS, J.P. Medicinal plants of the caatinga (semiarid) vegetation of NE Brazil: A quantitative approach. Journal of Ethnopharmacology, v. 114, p. 325-354, 2007a.

ALENCAR, N.L.; ARAÚJO, T.A.A.; AMORIM, E.L.C.; The Inclusion and Selection of Medicinal Plants in Traditional Pharmacopoeias-Evidence in Support of the Diversification Hypothesis. Economic Botany. v.64, n.1, p.68-79, 2010.

ALMEIDA, C.F.C.B.R.; ALBUQUERQUE, U.P. Uso e conservação de plantas e animais medicinais no estado de Pernambuco (Nordeste do Brasil): um estudo de caso. Interciência, v.26, p.276-285, 2002.

ALMEIDA, C.F.C.B.R.; SILVA, T.C.L.; AMORIM, E.L.C.; MAIA, M.B.S.; ALBUQUERQUE, U.P.; Life strategy and chemical composition as predictores of the selection of medicinal plants from the caatinga (Northeast Brazil). Journal of arid Enviroments. v.62, p.127-142, 2005.

ALMEIDA, C.F.C.B.R; AMORIM, E.L.C.; ALBUQUERQUE, U.P.; MAIA, M.B.S. Medicinal plants popularly used in the Xingó region - a semi-arid location in northeastern Brazil. Journal of Ethnobiology and Ethnomedicine, v. 2, n.15, p. 1-7, 2006.

ALVIANO, W.S.; ALVIANO, D.S.; DINIZ, C.G.; ANTONIOLLI, A.R.; ALVIANO, C.S.; FARIAS, L.M.; CARVALHO, M.A.R.; SOUZA, M.M.G.; BOLOGNESE, A.M. In vitro antioxidant potential of medicinal plant 
extracts and their activities against oral bacteria based on Brazilian folk medicine. Archives of oral biology, n.53, p. 545-552, 2008.

ATTA, A.H.; ALKOFAHI, A. Anti-nociceptive and antiinflammatory effects of some Jordanian medicinal plant extracts. Journal of Ethnopharmacology, v. 60, n.2, p. 117-124, 1998.

BARBALHO, S.M.; MACHADO, F.M.V.F.; GUIGER, E.L.; SILVA, P.H.; SILVA, V.S.; OSHIIWA, M.; GOULART, R.A. Espécies de Mentha podem auxiliar na redução de Fatores de Risco Vascular em pacientes Diabéticos. Revista Saúde e Pesquisa, v. 4, n. 3, p. 387-392, 2011.

BENNETT, B.C.; PRANCE, G.T. Introduced plants in the indigenous pharmacopoeia of Northern South America. Economic Botany, v.54, n.1, p.90-102. 2000.

BOTELHO, M.A.; RAO, V.S.; MONTENEGRO, D.; BANDEIRA, M.A.M.; FONSECA, S.G.C.; NOGUEIRA, N.A.P.; RIBEIRO, R.A.; BRITO, A.C. Effects of a herbal gel containing carvacrol and chalcones on alveolar boné resorption in rats on experimental periodontitis. Phytopherapy research v. 22, p. 442-449, 2008.

BRASIL. Ministério da Saúde RENISUS. Relação nacional de plantas medicinais de interesse ao SUS. Espécies vegetais. 2009. Disponível em: <http:// portal.saude.gov.br/portal/arquivos/pdf/RENISUS.pdf>. Acesso em: 15 mai. 2013.

BRASILEIRO, M.T.; EGITO, A.A.; LIMA, J.R. RANDAU, K.P.; PEREIRA, G.C.; NETO, P.J.R.. Ximenia americana L.: Botânica, química e farmacologia no interesse da tecnologia farmacêutica. Revista Brasileira de Farmácia, v. 39, p. 164-167, 2008.

CARTAXO, S.L.; SOUZA, M.M.A.; ALBUQUERQUE, U.P. Medicinal plants with bioprospecting potential used in semi-arid northeastern Brazil. Journal of Ethnopharmacology. v.131, p. 326-342, 2010.

CRUZ, M.C.S., SANTOS, P.O, BARBOSA JR. A.M., MELO, D.L.F.M, ALVIANO, C.S., ANTONIOLLI, A.R, ALVIANO, D.S, TRINDADE, R.C. Antifungal activity of Brazilian medicinal plants involved in popular treatment of mycoses. Journal of Ethnopharmacology. n.111, p.409-412. 2007.

IPECE - Instituto de Pesquisa e Estratégia Econômica do Ceará. Perfil básico municipal, 2010. Disponível em: <http://www.ipece.com.br>. Acesso em: 25 de agosto. 2013.

IPECE. Ceará em Mapas: Caracterização territorial. Disponível em: <http://www2.ipece.ce.gov.br>. Acesso em: 15 de março de 2014.

JANNI, K.D.; BASTIEN, J.W. Exotic Botanils in the Kallawaya Pharmacopoeia. Economic Botany, v.58, p.274-279, 2004.

JUNIOR, W.S.F.; LADIO, A.H.; ALBUQUERQUE, U.P. Resilience and adaptation in the use of medicinal plants with suspected anti-inflammatory activity in the Brazilian Northeast. Journal of Ethnopharmacology, n.138, p. 238-252. 2011.

LEAL, L.K.A.M., CANUTO, K.M., COSTA, K.C.S., NOBREJÚNIOR, H.V., VASCONCELOS, S.M., SILVEIRA, E.R., FERREIRA, M.V.P., FONTENELE, J.B., ANDRADE, G.M., VIANA, G.S.B., Effects of amburoside A and isokaempferide, polyphenols from Amburana cearensis, on rodent inflammatory processes and myeloperoxidase activity in human neutrophils. Basic and Clinical
Pharmacology and Toxicology, N.104, p.198-205. 2008.

LEITE, J. P. V.; FERNANDES, J. M.; FAVARO, L. V; GONTIJO, D. C.; MAROTTA, C.P. B.; SIQUEIRA, L. C.; MAIA, R. T.; GARCIA, F. C. P., Plantas medicinais no entorno do Parque Estadual da Serra do Brigadeiro. MG. BIOTA, v.1, n.4, p.16-34, 2008.

LUCENA, R.F.P., NASCIMENTO, V.T.; ARAÚJO, E.L.; ALBUQUERQUE, U.P. Local Uses of Native Plants in a Area of Caatinga Vegetation (Pernambuco, NE Brazil). Ethnobotanical Research \& Applications, v. 6 p. 03-13. 2008.

LUCENA, R.F.P.; FARIAS, D.C.; CARVALHO, T.K.N.; LUCENA, C.M.; VASCONCELOS NETO, C.F.A.; ALBUQUERQUE, U. P. Conhecimento tradicional de Myracrodruon Urundeuva Allemão por comunidades tradicionais no Semiárido do Nordeste do Brasil. Sitientibus série Ciências Biológicas, v.2, p. 255-264, 2011.

MACIEL, M.A.M.; PINTO, A.C.; V.F. VEIGA. JR.; GRYNBERG, N.F.; ECHEVARRIA, A. Plantas Medicinais: A Necessidade de Estudos Multidisciplinares. Química Nova, v. 25, n. 3, p. 429-438, 2002.

MARINHO, M.G.V.; SILVA, C.C.; ANDRADE, L.H.C. Levantamento etnobotânico de plantas medicinais em área de caatinga no município de São José de Espinharas, Paraíba, Brasil. Revista Brasileira de Plantas Medicinais, v.13, n.2, p.170-182, 2011.

MARTIN, G.J. Etnobotany: a methods manual. New York: Chapman and Hall, London, 1995. 276p.

MATTOS, S.H.; INNECCO, R.; MARCO, C.A.; ARAÚJO, A.V. Plantas medicinais e aromáticas cultivadas no Ceará: tecnologia de produção e óleos essenciais. Fortaleza: Banco do Nordeste do Brasil, 2007. p.61-63.

MORAIS, S.M.; DANTAS, J.D.P.; SILVA, A.R.A.; MAGALHÃES, E.F. Plantas medicinais usadas pelos índios Tapebas do Ceará. Revista Brasileira de Farmacognosia, v.15, p.169-177, 2005

MORI, S.A.; BONN, B.M.; CARVALHO, A.M.; SANTOS, T.S. Southen Bahian Forests. Botanical Review, v.49, p.155-232, 1989.

MOSCA, V.P.; LOIOLA, M.I.B. Uso popular de plantas medicinais no Rio Grande do Norte, Nordeste do Brasil. Revista Caatinga. v.22, n.4, p.225-234, 2009.

NOGUEIRA, J.C.R. DINIZ, M.F.M.; EDELTRUDES, O. Atividade antimicrobiana invitro de produtos vegetais em otite externa aguda. Revista Brasileira de Otorrinolaringologia, v.74, n.1, p. 118-24, 2008.

OLIVEIRA, F.C., ALBUQUERQUE, U.P., FONSECAKRUEL, V.S., HANAZAKI, N. Avanços nas pesquisas etnobotânicas no Brasil. Acta Botanica Brasilica v.23, p.590-605, 2009.

OLIVEIRA, F.C.S.; BARROS, R.F.M.; MOITA NETO, J.M. Plantas medicinais utilizadas em comunidades rurais de Oeiras, semiárido piauiense. Revista Brasileira de Plantas Medicinais, Botucatu, v.12, n.3, p.282-301, 2010b.

OLIVEIRA, G.L.; OLIVEIRA, A.F.M.; ANDRADE, L.H.C. Plantas medicinais utilizadas na comunidade urbana de Muribeca, Nordeste do Brasil. Acta botânica brasílica. v.24, n.2, p.571-577. 2010a.

OMS - Organização Mundial de Saúde. Classificação Estatística Internacional de Doenças e Problemas 
Relacionados à Saúde. Décima Revisão, vol. I. <http:// www.who.int/classifications/icd/en>. 2007.

RAGHAV, S.K.; GUPTA, B.; AGRAWAL, C.; GOSWAMI, K.; DAS, H.R. Anti-inflammatory effect of Ruta graveolens L. in murine macrophage cells. Journal of Ethnopharmacology, v.104, n.1-2, p.234-239, 2006.

ROQUE, A.A.; ROCHA, R.M.; LOIOLA, M.I.B. Uso e diversidade de plantas medicinais da Caatinga na comunidade rural de Laginhas, município de Caicó, Rio Grande do Norte (Nordeste do Brasil). Revista Brasileira de Plantas Medicinais, Botucatu, v.12, n.1, p.31-42, 2010.

SÁ, R.A.; GOMES, F.S.; NAPOLEÃO, T.H.; SANTOS, N.D.L.; MELO, C.M.L.; GUSMÃO, N.B.; COELHO, L. C.B.B.; PAIVA, P.M.G.; BIEBER, L.W. Antibacterial and antifungal activities of Myracrodruon urundeuva heartwood. Wood Science and Technology, v. 4, p. 85-95, 2009.

SHELLEY, B.C.L. Ethnobotany and the process of drug discovery: A laboratory exercise. The American Biology Teacher, v.71, n.9, p.541-547, 2009.

SILVA, A.C.O.; ALBUQUERQUE, U.P. Woody medicinal plants of the caatinga in the state of Pernambuco (Northeast Brazil). Acta Botanica Brasilica, v.19, n.1, p.17-26, 2005.

SILVA, K.L.; FILHO, C.V. Plantas do Gênero Bauhinia: Composição química e potencial farmacológico. Quimica Nova, v.25, n.3, p.449-454, 2002.

SILVA, V.A.; ANDRADE, L.H.C.; ALBUQUERQUE, U.P. Revising the Cultural Significance Index: The Case of the Fulni-ô in Northeastern Brazil. Field Methods, v.18, n.1, p.98-108, 2006.

SILVA, V.A.; NASCIMENTO, V.T.; SOLDATI, G.T.; MEDEIROS, M.F.T.; ALBUQUERUQUE, U.P. Etnobotânica aplicada à conservação da biodiversidade. In: ALBUQUERQUE, U.P.; LUCENA, R.F.P.; CUNHA, L.V.F.C. Métodos e técnicas na pesquisa etnobiológica e etnoecológica. NUPPEEA, 2010.

SIMÕES, C.M.O.; SCHENKEL, E.P.; GOSMANN, G.; MELLO, J.C.P.; MENTZ, L.A.; PETROVICK, P.R. Farmacognosia: da planta ao medicamento. $5^{\mathrm{a}}$ ed. Porto Alegre/Florianópolis: Editora da UFRGS / Editora UFSC, 2003.

SOUZA, R.K.D. Etnofarmacologia de Plantas Medicinais do Carrasco no Nordeste do Brasil, 2012. p.79, Dissertação (Mestrado em Bioprospecção Molecular -Biodiversidade), Universidade Regional do Cariri, Crato-CE.

SOUZA, S.M.C.; AQUINO, L.C.M.; MILACH JR, A.C.; BANDEIRA, M.A.M.; NOBRE, M.E.P.; VIANA, G.S.B. Antiinflammatory and antiulcer properties of tannins from Myracrodruon urundeuva Allemão (Anacardiaceae) in rodents. Phytotherapy Research, v. 21, p. 220-225, 2007.

TROTER, R.; LOGAN, M. Informant consensus: anew approach for identifying potentially effective medicinal plants. In: ETKIN, N. L. (Ed.). Indigenous medicine and diet: biobehavioural approaches. New York: Redgrave Bedford Hills. 1986, p. 91-112. 